\title{
Transient and sustained incentive effects on electrophysiological indices of cognitive control in younger and older adults
}

\author{
Ryan S. Williams ${ }^{1,2} \cdot$ Farrah Kudus $^{1} \cdot$ Benjamin J. Dyson $^{1,3} \cdot$ Julia Spaniol $^{1}$
}

Published online: 1 February 2018

(C) Psychonomic Society, Inc. 2018

\begin{abstract}
Preparing for upcoming events, separating task-relevant from task-irrelevant information and efficiently responding to stimuli all require cognitive control. The adaptive recruitment of cognitive control depends on activity in the dopaminergic reward system as well as the frontoparietal control network. In healthy aging, dopaminergic neuromodulation is reduced, resulting in altered incentive-based recruitment of control mechanisms. In the present study, younger adults (18-28 years) and healthy older adults (66-89 years) completed an incentivized flanker task that included gain, loss, and neutral trials. Event-related potentials (ERPs) were recorded at the time of incentive cue and target presentation. We examined the contingent negative variation (CNV), implicated in stimulus anticipation and response preparation, as well as the P3, which is involved in the evaluation of visual stimuli. Both younger and older adults showed transient incentive-based modulation of CNV. Critically, cue-locked and targetlocked P3s were influenced by transient and sustained effects of incentives in younger adults, while such modulation was limited to a sustained effect of gain incentives on cue-P3 in older adults. Overall, these findings are in line with an age-related reduction in the flexible recruitment of preparatory and target-related cognitive control processes in the presence of motivational incentives.
\end{abstract}

Keywords Aging $\cdot$ Flanker task $\cdot$ Event-related potentials $\cdot \mathrm{CNV} \cdot \mathrm{P} 3 \cdot$ Reward

The human attentional system is served by a frontoparietal control network that delivers top-down signals to maintain task-relevant sets, prepare motor responses, and detect and resolve perceptual conflict, among other functions (Corbetta, Patel, \& Shulman, 2008; Hopfinger, Buonocore, \& Mangun, 2000). While these control processes allow us to accomplish a wide range of tasks in our everyday environments, the engagement of such processes can be effortful, particularly when task demands are high, or when attention must be sustained over an extended duration. According to a neuroeconomic model of cognitive control, the engagement of such processes follows a cost-benefit trade-off (Kool \& Botvinick, 2014; Massar, Lim, Sasmita, \& Chee, 2016; Westbrook \& Braver, 2015). In this view, control processes are engaged flexibly, such that high

Julia Spaniol

jspaniol@psych.ryerson.ca

1 Ryerson University, 350 Victoria St, Toronto, ON M5B 2K3, Canada

2 University of Toronto, 27 King's College Circle, Toronto, ON M5S, Canada

3 University of Sussex, Falmer BN1 9QH, UK payoffs increase, and low payoffs decrease, the likelihood of engagement.

In line with this reasoning, a number of studies have employed experimental tasks designed to permit inferences regarding the effect of extrinsic incentives (e.g., monetary bonuses and penalties) on the engagement of cognitive control processes. The monetary incentive delay task (MID; Knutson, Westdorp, Kaiser, \& Hommer, 2000), for example, is a cued target detection task in which trial-varying incentive and neutral cues inform participants of the prospect of gaining or losing a monetary incentive in advance of target presentation. In such tasks, cues associated with incentive prospect consistently elicit faster responses to targets, and in some cases reduce targetdistractor interference when stimulus conflict is present (e.g., Krebs, Boehler, \& Woldorff, 2010; Padmala \& Pessoa, 2011).

Beyond these behavioral effects, incentive cues elicit functional changes in the brain's mesolimbic reward circuit prior to target presentation. Regions in this circuit that are sensitive to incentive cues include the ventral striatum, substantia nigra/ ventral tegmental area (SN/VTA), and the thalamus (Cho et al., 2013; Ivanov et al., 2012; Knutson et al., 2000; Krebs, Boehler, Roberts, Song, \& Woldorff, 2012; Padmala \& Pessoa, 2011; Schott et al., 2008). Dopaminergic transmission 
is principally involved in this process, with increased activation of the ventral striatum to incentive cues associated with a parallel increase in the release of dopamine to this area (Schott et al., 2008). Importantly, the frontoparietal control network also shows enhanced activation following incentive cues, with observations of functional coupling between mesolimbic areas and the intraparietal sulcus, a key region involved in the endogenous control of attention (Gillebert et al., 2011; Ivanov et al., 2012; Padmala \& Pessoa, 2011). Most of these studies have focused on gain rather than loss incentive cues. When both types of cues were included, they produced similar activation of the mesolimbic reward system (Carter, MacInnes, Huettel, \& Adcock, 2009). The functional overlap in the processing of gain and loss incentive cues has also been demonstrated in the context of risky decisions, as gambles involving high potential gains and those involving high potential losses exhibit similar activation of the ventral striatum (Tom, Fox, Trepel, \& Poldrack, 2007).

Findings that suggest a link between incentivemodulated activation of the frontoparietal control network and striatal dopamine transmission are particularly relevant in the context of aging. Animal and human studies provide converging evidence for age-related decline in the number of striatal dopamine receptors (Henry, Filburn, Joseph, \& Roth, 1986; Kaasinen et al., 2000; Rinne et al., 1993; Wang et al., 1998). Striatal receptor loss is associated with impaired reward-based learning in old age (e.g., Chowdhury et al., 2013; Mell et al., 2009; Weiler, Bellebaum, \& Daum, 2008), and may also reduce sensitivity to incentive cues in older adults. Consistent with this hypothesis, some authors report reduced responses to incentive cues in both the mesolimbic reward circuit and frontoparietal control network in older adults (Dreher, Meyer-Lindenberg, Kohn, \& Berman, 2008; Vink, Kleerekooper, van den Wildenberg, \& Kahn, 2015; Schott et al., 2007). In contrast to these findings, however, there is some evidence that the decreased striatal response to incentives cues may be specific to loss but not gain incentives (Samanez-Larkin et al., 2007). Further, it has been reported that older adults not only activate the mesolimbic reward circuit to the same extent as younger adults in response to incentive cues but additionally recruit compensatory activation of more extensive cortical networks (Spaniol, Bowen, Wegier, \& Grady, 2015).

As the above discussion highlights, much of the literature concerned with incentive-based modulation of cognitive control in older adults has relied on functional magnetic resonance imaging (fMRI). While these studies have provided valuable insights into the functional neuroanatomy of incentive processing in healthy aging, relatively little is known regarding the contribution of age to the temporal dynamics of incentive processing and its impact on cognitive control. Electroencephalography (EEG), offering rapid recordings of neurophysiological activity, are a method of choice in this regard.

One ERP component implicated in cognitive control is the P3 - a family of positive-going deflections present along the midline occurring roughly $300-600 \mathrm{~ms}$ following a visual stimulus (for a review, see Polich, 2007). When this component is elicited by task-relevant cues, P3 likely reflects engagement of proactive cognitive control, as larger amplitudes are generated for cues that are predictive of imperative rather than nonimperative stimuli (Bekker, Kenemans, \& Verbaten, 2004; Jonkman, 2006). A P3 is also elicited at the time of target presentation. When target stimuli are presented among interfering stimuli, P3 is thought to index an evaluative decisionmaking process - peaking later when conflict is present versus absent (Gajewski, Stoerig, \& Falkenstein, 2008; Purmann, Badde, Luna-Rodriguez, \& Wendt, 2011). With respect to aging, cue-P3 is delayed in older adults and exhibits less differentiation on the basis of cue significance (Hämmerer, Li, Müller, \& Lindenberger, 2010; Kray, Eppinger, \& Mecklinger, 2005; Kropotov, Ponomarev, Tereshchenko, Müller, \& Jäncke, 2016). Similarly, target-P3 in older relative to younger adults is delayed, more frontally distributed, and is attenuated by conflict (Reuter, Voelcker-Rehage, Vieluf, Lesemann, \& Godde, 2016; Wild-Wall, Falkenstein, \& Hohnsbein, 2008; Williams et al., 2016).

In addition to $\mathrm{P} 3$, the contingent negative variation $(\mathrm{CNV})$ is also relevant to the engagement of cognitive control processes. This slow-wave component, observed at frontocentral sites, is thought to index the extent to which individuals utilize informative cues. It involves both a temporal orienting aspect, in which one anticipates the onset of a relevant stimulus, and a motor-based aspect related to one's preparedness to respond to the relevant stimulus (Funderud et al., 2012; Gómez, Flores, \& Ledesma, 2007; Nagai et al., 2004; Pfeuty, Ragot, \& Pouthas, 2005). Interestingly, the amplitude of this component is sometimes greater in older and middle-aged adults relative to younger adults, particularly when task demands are high (Wild-Wall, Hohnsbein, \& Falkenstein, 2007). It has been argued that such age differences are attributable to greater recruitment of compensatory attentional resources (WildWall et al., 2007).

In line with the view that cognitive control is sensitive to motivational factors, the ERP components described thus far have all been shown to be responsive to the presence of incentives. In the case of cue-P3, larger amplitudes are observed for incentive cues compared with nonincentive cues, particularly in the context of gain (rather than loss) incentives (Schevernels, Bombeke, Krebs, \& Boehler, 2016; Schevernels, Krebs, Santens, Woldorff, \& Boehler, 2014; Pfabigan et al., 2014; van den Berg, Krebs, Lorist, \& Woldorff, 2014). Similarly, CNV exhibits greater amplitude 
when an incentive is at stake versus when no incentive is at stake (e.g., Plichta et al., 2013; van den Berg et al., 2014; but see Broyd et al., 2012; Schevernels et al., 2016). At the time of target presentation, larger P3 amplitudes are generated for targets for which an incentive can be earned, irrespective of incentive valence (Broyd et al., 2012; Krebs, Boehler, Appelbaum, \& Woldorff, 2013). Further, combined EEGfMRI studies have directly related P3 and CNV components to activity in the mesolimbic reward circuit (Pfabigan et al., 2014; Plichta et al., 2013).

Whether incentive effects on P3 and CNV differ for younger and older adults remains largely unknown. To the best of our knowledge, only one study to date has examined the effects of incentive prospect on these components in healthy older adults. Schmitt, Ferdinand, and Kray (2015) examined anticipatory engagement processes in response to gain, loss, and neutral incentive cues in younger and older adult populations. In this study, an increase in cue-P3 amplitude was observed in response to gain and loss cues relative to neutral cues in both younger and older adults, with a more pronounced incentive-related enhancement in younger adults. CNV amplitude was sensitive to loss but not gain incentives in younger adults, whereas older adults showed no incentivebased modulation of CNV amplitude (Schmitt et al., 2015).

Additionally, there is evidence to suggest that the effect of incentives on behavior may extend beyond transiently activated stimulus-reward associations. For example, using both a task-switching paradigm and a working memory task, Savine, Beck, Edwards, Chiew, and Braver (2010) found that participants were faster to respond to neutral trials intermixed within blocks containing incentive trials compared with when such trials were presented independently of incentive trials. A similar finding was reported more recently by Marini, van den Berg, and Woldorff (2015) using a cued Eriksen flanker task (Eriksen \& Eriksen, 1974). Outside of these behavioral effects, sustained incentive effects have also been shown to influence physiological measures such as fMRI activation and pupil dilation. Jimura, Locke, and Braver (2010), for example, observed both transient and sustained incentive-related enhancements of behavioral performance, the latter being accompanied by sustained activation of the lateral prefrontal cortex in rewarding contexts, particularly in individuals high in reward sensitivity. Similarly, Chiew and Braver (2013) found not only transient increases in pupil dilation in response to incentive cues but also sustained effects, with larger pretrial pupil diameter for neutral trials presented among incentive trials relative to neutral trials presented in neutral-only blocks. However, to our knowledge, no study to date has independently examined transient and sustained effects of incentives on ERP correlates of cognitive control, nor has there been any investigation in this area involving older adults.

In the present study, we aimed to extend findings regarding the influence of incentive cues on ERP signatures previously associated with incentive-based modulation of cognitive control in younger and older adult populations using an incentivized flanker task. In line with Schmitt et al. (2015), we were interested in examining differences in P3 and CNV in response to incentive cues versus neutral cues. Motivated by the aforementioned evidence for incentive-based modulation of target-related electrophysiological responses in younger adults, we also examined P3 in response to the target presentation. In light of the evidence of transient and sustained effects of incentives on cognitive control (e.g., Chiew \& Braver, 2013; Jimura et al., 2010; Marini et al., 2015), we were also interested in comparing the temporal extent of incentive effects in younger and older adults. We thus employed a design in which incentive blocks included incentive and neutral trials, allowing for an assessment of transient (i.e., trial-specific) effects of incentive, and neutral blocks that included neutral trials only. The comparison between neutral trials presented in the context of incentive blocks and neutral trials presented in the context of neutral blocks permitted an assessment of sustained (i.e., context-driven) incentive effects. To our knowledge, no prior aging studies have investigated age differences in transient and sustained incentive effects on cognitive control. Finally, similar to Schmitt et al. (2015), we included both gain and loss incentives. This was motivated by evidence that older adults display a "positivity bias," favoring positively valenced over negatively valenced information (Mather, \& Carstensen, 2005; Reed \& Carstensen, 2012; Samanez-Larkin et al., 2007). This raises the possibility that loss incentives may be less potent than gain incentives for older adults.

We predicted that reduced striatal dopaminergic transmission associated with healthy aging would lead to a reduction in incentive-based modulation of behavioral and ERP measures of cognitive control. In younger adults, we expected that incentives would lead to faster responding and reduced distractor interference, in both a transient and sustained manner. Further, we expected to observe larger amplitudes for cueP3, CNV, and target-P3 when incentives were present. Again, we expected that these effects would be attenuated in older adults, potentially more so for loss than for gain incentives.

\section{Method}

\section{Participants}

Twenty-six younger adults and 29 older adults participated in the present study. Younger adults were recruited via online community postings and advertisements posted around Ryerson University, Toronto, Ontario. Older adults were recruited through the Ryerson Senior Participant Pool. All participants were screened over the phone prior to the study, with those included reporting to have normal or corrected-to- 
normal vision and hearing, and to be free of any major medical, neurological, or psychological problems. Possible dementia-related impairment was screened on the day of testing using the Mini Mental State Exam (MMSE; Folstein, Folstein, \& McHugh, 1975). Two older adults had to be excluded on this basis for failing to meet our minimum cutoff score of 26 out of a possible 30 points. After further excluding participants who failed to meet our performance criteria (described below), or had an excessive number of artifacts in the EEG recording, the final sample consisted of 24 younger adults and 24 older adults. Group characteristics for the final sample show typical age-related differences in cognitive and affective measures (see Table 1). Written informed consent was obtained at the beginning of the experiment for each participant, and all participants were compensated \$25 in addition to a bonus obtained during the experiment. All study procedures were approved by the Research Ethics Board of Ryerson University.

\section{Apparatus and design}

Participants were seated approximately $60 \mathrm{~cm}$ from the computer monitor. The incentivized flanker task was delivered to this monitor through Presentation software (Version 16.5; Neurobehavioral Systems, Berkeley, CA). A black background was used for the task, with all other stimuli appearing in white.

An example of a trial used in the incentivized flanker task is presented in Fig. 1. Each trial began with a centrally presented fixation cross, the duration of which was randomly selected on each trial from a uniform distribution ranging from 400 to $1,600 \mathrm{~ms}$. A dollar sign or an ampersand was then presented for $400 \mathrm{~ms}$, representing an incentive or neutral (i.e., nonincentive) trial, respectively. The central fixation cross then returned for a jittered duration (i.e., $600 \mathrm{~ms}$ or $900 \mathrm{~ms}$ ), such that the cue could not be used to reliably predict the onset of the target. Target displays consisted of five horizontally aligned arrows presented to the center of the screen. Each arrow subtended a visual angle of $.38^{\circ}$ vertically $\times .63^{\circ}$ horizontally at the viewing distance of $60 \mathrm{~cm}$, with the entire sequence subtending a horizontal angle of $3.53^{\circ}$. In some cases, all of the arrows faced in the same direction (all left or all right; congruent target condition), while in other cases the central arrow faced opposite the outer arrows (incongruent target condition). Participants responded to the direction of the central arrow with their index fingers by pressing the " $x$ "

Table 1 Group characteristics

\begin{tabular}{|c|c|c|c|c|c|c|}
\hline & \multicolumn{2}{|c|}{ Younger adults } & \multicolumn{2}{|c|}{ Older adults } & \multirow[t]{2}{*}{$t(46)$} & \multirow[t]{2}{*}{$p$} \\
\hline & $M$ & $S D$ & $M$ & SD & & \\
\hline$N$ & 24 & - & 24 & - & - & - \\
\hline$N$ (Female) & 15 & - & 16 & - & - & - \\
\hline Age, years & 20.50 & 2.47 & 73.33 & 6.66 & 36.46 & $<.001$ \\
\hline Age range, years & $18-28$ & - & $66-89$ & - & - & - \\
\hline Education, years & 13.88 & 1.78 & 16.08 & 2.41 & 3.61 & .001 \\
\hline MHV & 16.79 & 4.95 & 23.54 & 4.54 & 4.92 & $<.001$ \\
\hline DSST & 86.63 & 12.73 & 69.71 & 14.90 & 4.23 & $<.001$ \\
\hline MMSE & 29.38 & .82 & 28.42 & 1.28 & 3.08 & .004 \\
\hline \multicolumn{7}{|l|}{ BIS/BAS } \\
\hline Inhibition & 20.75 & 3.42 & 18.25 & 4.07 & 2.31 & .026 \\
\hline Drive & 10.96 & 2.66 & 10.71 & 2.77 & .32 & .751 \\
\hline Fun seeking & 12.33 & 1.81 & 11.25 & 2.03 & 1.95 & .057 \\
\hline Reward responsivity & 17.50 & 2.50 & 16.13 & 2.05 & 2.08 & .043 \\
\hline \multicolumn{7}{|l|}{ PANAS } \\
\hline Positive affect & 31.04 & 6.40 & 32.88 & 8.74 & .83 & .412 \\
\hline Negative affect & 12.25 & 2.51 & 10.83 & 1.01 & 2.57 & .015 \\
\hline \multicolumn{7}{|l|}{ DASS-21 } \\
\hline Depression & 9.83 & 10.09 & 3.33 & 4.78 & 2.85 & .007 \\
\hline Anxiety & 8.67 & 7.79 & 2.08 & 2.17 & 3.99 & $<.001$ \\
\hline Stress & 13.33 & 10.71 & 5.92 & 4.95 & 3.08 & .004 \\
\hline
\end{tabular}

Note. MHV = Mill Hill Vocabulary Scale (Raven, 1982); DSST = Digit Symbol Substitution Task (Wechsler, 1955); MMSE = Mini Mental State Exam (Folstein et al., 1975); BIS/BAS = Behavioural Inhibition System and Behavioural Activation Scales (Carver \& White, 1994); PANAS = Positive and Negative Affect Schedule (Watson, Clark, \& Tellegen, 1988); DASS-21 = Depression Anxiety Stress Scales (Lovibond \& Lovibond, 1995) 


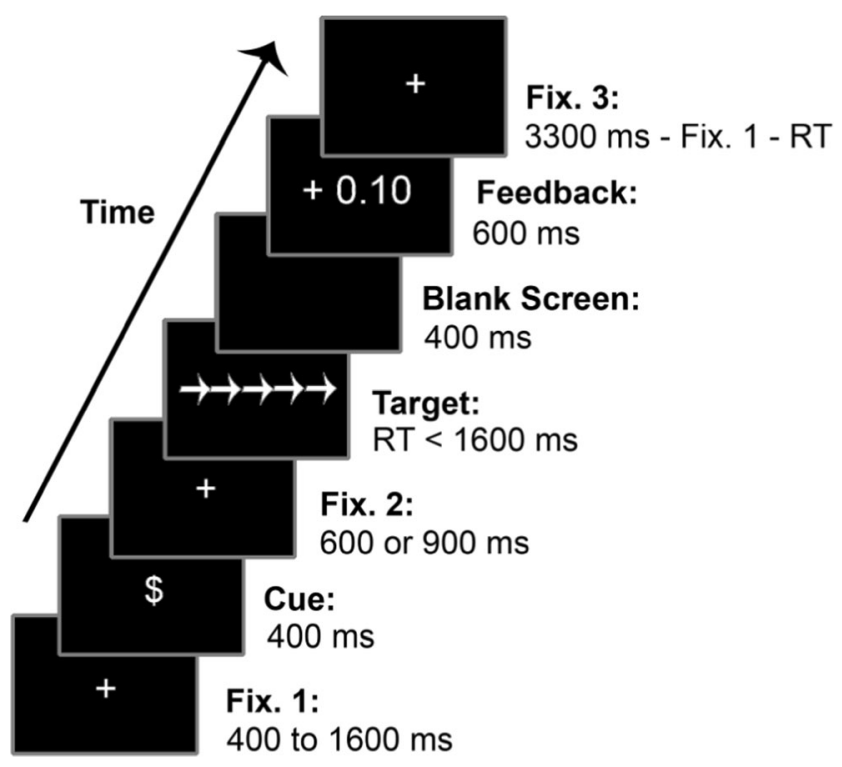

Fig. 1 Incentivized flanker task. Represented is a single gain-incentive (GI) trial with positive feedback. Each trial began with a random fixation period that preceded the onset of either an incentive cue $(\$)$ or a nonincentive cue (\&). Participants continued to fixate centrally following the offset of the cue until a sequence of five arrows was presented. Participants were allowed up to $1,600 \mathrm{~ms}$ to respond to the direction of the central arrow (left/right). Shortly after responding, feedback was provided, followed by a final fixation period

key for left responses and “," key for right responses using a standard QWERTY keyboard. Target stimuli remained onscreen until a response was registered or until a maximum response time of 1,600 ms was reached. A blank screen was then presented for the next $400 \mathrm{~ms}$, followed by feedback for the next $600 \mathrm{~ms}$. Finally, the central fixation returned until a total trial duration of $5,300 \mathrm{~ms}$ or $5,600 \mathrm{~ms}$ was reached, depending on the length of the second fixation. This ensured that the task would take the same amount of time to complete for all participants - that is, responding quickly did not shorten the length of the experiment since trial duration was equivalent for all participants.

The experiment included three block types: two types of incentive blocks (gain and loss), as well as neutral blocks. Within gain blocks, incentive trials communicating an opportunity to earn $\$ .10$ were intermixed with neutral trials. Within loss blocks, incentive trials communicating the threat of losing $\$ .10$ were intermixed with neutral trials. Neutral blocks included neutral trials only. We thus distinguish five trial types: incentive trials within gain blocks (GI), neutral trials within gain blocks (GN), incentive trials within loss blocks (LI), neutral trials within loss blocks (LN), and neutral trials within neutral blocks (NN).

In order to gain the reward for GI trials and prevent the loss for LI trials, participants had to be both accurate and faster than a target time when responding to the target. The task employed performance-adaptive response deadlines for these incentive trials so that participants would be successful on approximately $70 \%$ of these trials, which is comparable to the success rate typically employed for the MID task and its analogues (e.g., Cho et al., 2013; Knutson et al., 2000; Krebs et al., 2010; Spaniol et al., 2015; van den Berg et al., 2014). To this end, we adjusted the target response deadline based on the participant's performance on GI and LI trials, respectively. Specifically, the response deadline was determined by participants' cumulative mean reaction time (RT) for correct responses in each incentive condition, plus an adjustable value that started out at zero. Each time a participant made a successful response while above the $70 \%$ success rate, $10 \mathrm{~ms}$ was subtracted from the adjustable value, thus shortening the target response deadline. When the proportion of successful responses dropped to $70 \%$, the adjustable value was reset to zero. While the success rate was below $70 \%, 10 \mathrm{~ms}$ was added to the adjustable value each time a slow or incorrect response was recorded, thus extending the response deadline. Additionally, a floor of $250 \mathrm{~ms}$ and a ceiling of $1,600 \mathrm{~ms}$ were set for the target response deadline. It is important to note that the target response deadline does not refer to how long the target display remained onscreen but rather denotes the temporal window during which a response was considered successful. As noted, the target always remained onscreen until a response was made or until 1,600 ms had elapsed.

To illustrate the effectiveness of the performanceadaptive response deadline procedure, Fig. 2 shows the cumulative success rates as a function of trial position for GI and LI conditions in both age groups. As can be seen, both younger and older adults achieved a success rate of approximately $65 \%-70 \%$ for much of the task, in both GI and LI conditions.

For GI trials, the feedback participants received was “ $\$ 0.10$ " for successful responses, and " $\$ 0.00$ ” for unsuccessful responses. For LI trials, participants were shown either “ $\$ 0.00$ ” for successful responses or " $-\$ 0.10$ ” for unsuccessful responses. The feedback given for GN, LN, and NN trials was always a string of hash marks (i.e., "\#\#\#\#”).

Participants completed two blocks of each block type, with block order counterbalanced across participants. Each gain block and each loss block included 96 trials, whereas neutral blocks included 48 trials, for a total of 480 total across the entire experiment. Within each block, each possible combination of cue, cue-target interval, and target congruency was presented an equal number of times (i.e., 12 trials each), in random order. Participants were informed of the block type prior to beginning each block. At the end of each block, participants were informed how much they had won or lost. In the case of neutral blocks, participants were informed that they had neither won nor lost any money. When all six blocks were completed, the total amount obtained during the task was presented. 
Gain-Incentive Trials

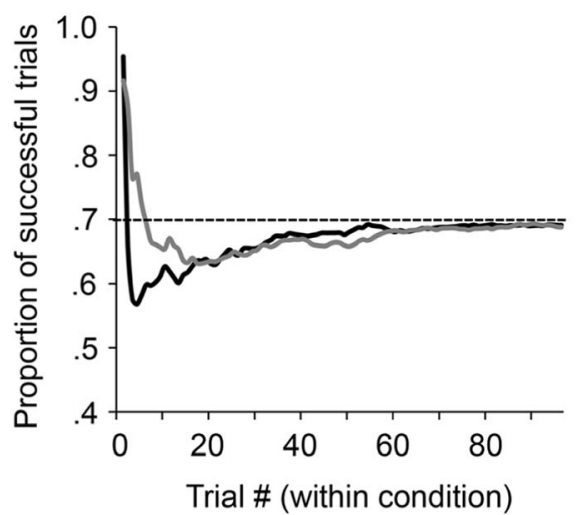

Loss-Incentive Trials

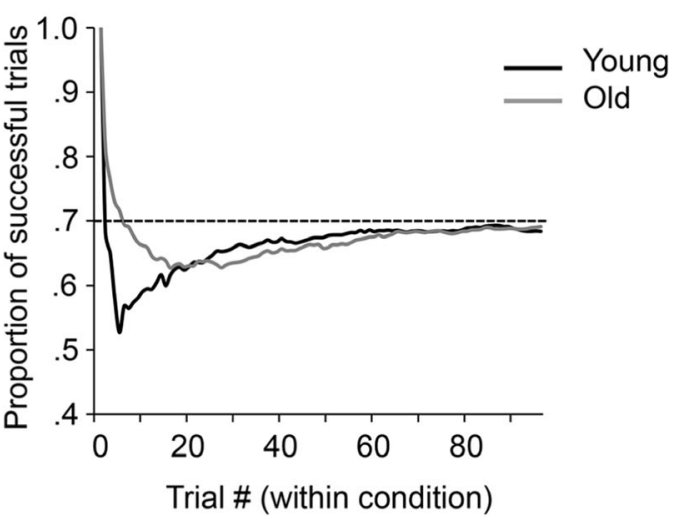

Fig. 2 Cumulative success rate for gain-incentive and loss-incentive trials in younger and older adults. Note. Two younger adults with incomplete data sets (i.e., excluded blocks) are not included in these plots

\section{Procedure}

For the incentivized flanker task, participants were brought to a soundproofed room and seated comfortably in front of the computer monitor. They were instructed to respond as quickly and as accurately as possible to the direction of the central arrows and then given a practice block consisting of 16 neutral trials. Afterwards, participants were told that they would be able to receive a monetary bonus during the task. They were told that during gain blocks, dollar signs prior to the target would indicate the possibility of gaining $\$ .10$, whereas these cues would indicate the possibility of losing $\$ .10$ during loss blocks. They were also told that they would have to be both accurate and faster than a target time set by the computer to earn, or prevent losing, the $\$ .10$ incentive. Participants then had a chance to practice both a gain block and a loss block (16 trials each). Each participant began the experimental trials with a starting balance of $\$ 15.00$. Following the experiment, participants completed a battery of neuropsychological tests, after which they were debriefed and compensated.

\section{ERP acquisition and processing}

Electroencephalographic (EEG) activity was continuously digitized for off-line processing using an ActiveTwo system (BioSemi; Amsterdam, Netherlands) with a band-pass filter of $208 \mathrm{~Hz}$ and a $512 \mathrm{~Hz}$ sampling rate. Recordings were acquired from $\mathrm{Ag} / \mathrm{AgCl}$ electrodes mounted in an elastic cap (Cortech Solutions; Wilmington, NC) at 64 scalp sites in accordance with the International 10-20 System. External electrodes were placed at the left and right mastoid. Horizontal and vertical movements for each eye were recorded using channels placed at the outer canthi and inferior orbits, respectively.

Off-line processing was conducted using EEGLAB (Version 13.5; Delorme \& Makeig, 2004) and ERPLAB (Version 5.1.1.; Lopez-Calderon \& Luck, 2014). EEG data were referenced to the average of the left and right mastoids and were resampled at $256 \mathrm{~Hz}$. High-pass $(0.1 \mathrm{~Hz}, 12 \mathrm{~dB} /$ octave) and low-pass (30 Hz, $24 \mathrm{~dB} /$ octave) filters were applied to the continuous data. The data were then epoched into 1,000-ms segments time-locked to cue and target stimuli (baseline corrected $200 \mathrm{~ms}$ prestimulus onset). Independent component analysis was used to correct artifacts (e.g., eye blinks, lateral eye movements; see Delorme, Sejnowski, \& Makeig, 2007). Epochs containing values exceeding a threshold of $\pm 75 \mu \mathrm{V}$ were automatically rejected. Participants with a total trial rejection rate greater than $30 \%$ were excluded from analysis. This was the case for three older adults, who were not included in the final sample.

\section{Behavioral data analysis}

In the event that a participant failed to record a response for $10 \%$ of responses in a block, the block was excluded from analyses. This was the case for one younger adult due to a technical error during a loss block. Further, blocks were excluded from analyses if a participant performed below $60 \%$ accuracy in a given condition of Trial Type $\times$ Congruency within a block. If more than one block needed to be excluded, the participant was excluded from analyses altogether. Two younger adults were excluded on this basis. Lastly, a gain block was excluded for a younger adult who performed at $58 \%$ accuracy for incongruent targets during GI trials in this block.

Accuracy and reaction time (RT) data were analyzed using separate mixed-factorial ANOVAs, consisting of the betweensubject factor of age (younger adults, older adults) and withinsubject factors of trial type (GI, GN, LI, LN, NN) and congruency (congruent, incongruent). In cases where Mauchly's sphericity test was significant, degrees of freedom were adjusted using the Huynh-Feldt correction method. Significant effects and interactions were followed up with two-tailed $t$ tests using the Benjamini-Hochberg procedure (Benjamini \& Hochberg, 1995) to correct for multiple comparisons, with 
significant values denoted by $p_{\mathrm{BH}}<.05$. Follow-up comparisons involving the factor of incentive were concerned with transient effects (i.e., GI vs. GN trials; LI vs. LN trials), sustained effects (i.e., GN vs. NN trials; $\mathrm{LN}$ vs. $\mathrm{NN}$ trials), and valence effects (i.e., GI vs. LI trials; GN vs. LN trials).

One concern was that the required criteria to gain or avoid losing incentives could have potentially led to faster responses at the expense of accuracy. Dambacher and Hübner (2015), for example, recently demonstrated that emphasizing speed during the flanker task impedes early response processes leading to a higher proportion of errors, particularly for fast responses. Moreover, using a task similar to the one employed here, Chiew and Braver (2016) did indeed find a speed-accuracy trade-off when incentive cues were combined with the flanker task. As such, we addressed the possibility of a speedaccuracy trade-off in the current task by further conducting two additional behavioral analyses.

First, we performed a distributional analysis of the flanker interference effect on accuracy as a function of RT. In line with previous studies, this was done using delta plots (Ridderinkhof, 2002; Ridderinkhof, Scheres, Oosterlaan, \& Sergeant, 2005; Roelofs, Piai, \& Rodriguez, 2011; Wylie, Ridderinkhof, Eckerle, \& Manning, 2007). As described by Ridderinkhof (2002), it is assumed that two parallel decision processes contribute to target responses, including an automatic process that is strongly influenced by the presence of conflicting information as well as a more deliberative process involved in the evaluation of the target stimulus. In this view, errors are thought to be most common for fast responses when conflict is present, since it is assumed that in such cases a decision threshold is reached by the automatic process before the more deliberative process can exert its control (Ridderinkhof, 2002). Delta plots were constructed by ordering individual participants' correct and incorrect responses on the basis of RT for each Trial Type $\times$ Congruency condition. The two younger adults with excluded blocks were not included in this analysis. Quartile marks were determined and used to segment the responses into four bins. For example, in a given condition, Quartile 1 included all responses with an RT greater than zero and less than or equal to the Quartile 1 mark, whereas Quartile 2 consisted of all responses with an RT greater than the Quartile 1 mark and less than or equal to the Quartile 2 mark, and so on. Mean RT and accuracy were then calculated for each quartile bin. The effect of response speed on flanker interference was then plotted for the various trial types as the difference in accuracy for congruent and incongruent targets positioned at the $x$ value that corresponded to the mean RT of congruent and incongruent targets for the given quartile bin. A mixedfactorial ANOVA including the factors age (younger adults, older adults), trial type (GI, GN, LI, LN, NN), and quartile-to-quartile interval (Quartile 1 to Quartile 2,
Quartile 2 to Quartile 3, Quartile 3 to Quartile 4) was performed on the slopes connecting adjacent quartile bins.

Second, we included an additional behavioral measure in order to take a potential speed-accuracy trade-off into consideration. Specifically, we analyzed a measure referred to as the inverse efficiency score (IES; Townsend \& Ashby, 1978). This measure is calculated as RT divided by the proportion of correct responses. As one can infer, low IES is associated with more efficient responses since both large RT values and high error rates increase estimates of this measure. As was the case for accuracy and RT, IES was entered into a mixedfactorial ANOVA consisting of the between-subject factor of age (younger adults, older adults), and within-subject factors of trial type (GI, GN, LI, LN, NN) and congruency (congruent, incongruent).

\section{ERP data analysis}

ERP analyses focused on cue-evoked and target-evoked activity. At the time of the cue, $\mathrm{P} 3$ and $\mathrm{CNV}$ amplitudes were measured. Cue-locked $\mathrm{P} 3$ was averaged at centroparietal sites $(\mathrm{CPz}$ and $\mathrm{Pz})$ and frontocentral sites $(\mathrm{FCz}$ and $\mathrm{Cz}$ ), respectively. Peak amplitudes at both sites were determined between $350 \mathrm{~ms}$ and $600 \mathrm{~ms}$ following target onset for each condition of Age $\times$ Trial Type. Amplitudes were then obtained using $100 \mathrm{~ms}$ windows, centered on peak latencies. Latency and amplitude measurements were then analyzed using mixedfactorial ANOVAs of age (younger adults, older adults), region (centroparietal, frontocentral), and trial type (GI, GN, LI, $\mathrm{LN}, \mathrm{NN}$ ). CNV was defined as the activity $700-1,000 \mathrm{~ms}$ following cue onset, averaged across frontocentral electrode sites $(\mathrm{FCz}$, and $\mathrm{Cz})$. These measurements were submitted to a mixed-factorial ANOVA, with one between-subjects factor, age (younger adults, older adults), and one within-subjects factor, trial type (GI, GN, LI, LN, NN). Target-based analyses focused exclusively on $\mathrm{P}$, following the procedure used for cue-locked P3, with the addition of the within-subjects factor of congruency (congruent, incongruent). Also, a slightly larger time window was considered (i.e., $300 \mathrm{~ms}-700 \mathrm{~ms}$ ) to determine peak latency in order to account for greater variability in the $\mathrm{P} 3$ response at the time of the target.

\section{Results}

\section{Behavioral results}

Accuracy and reaction time Means and standard deviations for the behavioral measures are presented in Table 2. Accuracy was influenced by age, $F(1.0,46.0)=12.3, p=.001, \eta_{\mathrm{p}}{ }^{2}=$ .021 ; congruency, $F(1.0,46.0)=108.1, p<.001, \eta_{\mathrm{p}}{ }^{2}=.701$; and trial type, $F(3.0,184.0)=15.1, p<.001, \eta_{\mathrm{p}}{ }^{2}=.025$. 
Table 2 Means $(M)$ and standard deviations $(S D)$ for behavioral data

\begin{tabular}{|c|c|c|c|c|c|c|c|c|c|c|c|c|}
\hline & & & \multicolumn{2}{|l|}{ GI } & \multicolumn{2}{|l|}{ GN } & \multicolumn{2}{|l|}{ LI } & \multicolumn{2}{|l|}{$\mathrm{LN}$} & \multicolumn{2}{|l|}{ NN } \\
\hline & & & $M$ & $(S D)$ & $M$ & $(S D)$ & $M$ & $(S D)$ & $M$ & $(S D)$ & $M$ & $(S D)$ \\
\hline \multirow[t]{4}{*}{ Accuracy (\% correct) } & \multirow[t]{2}{*}{ Young } & Congr. & 98.7 & $(2.9)$ & 99.5 & $(1.5)$ & 98.8 & $(2.2)$ & 99.6 & $(1.0)$ & 99.1 & (1.6) \\
\hline & & Incongr. & 84.6 & (8.4) & 92.0 & (7.6) & 84.9 & $(9.5)$ & 90.8 & $(9.2)$ & 91.5 & (6.4) \\
\hline & \multirow[t]{2}{*}{ Old } & Congr. & 99.8 & (.7) & 99.9 & (.4) & 99.4 & $(1.2)$ & 99.3 & (1.4) & 99.8 & $(.7)$ \\
\hline & & Incongr. & 91.6 & (7.4) & 94.8 & $(4.9)$ & 93.7 & $(5.6)$ & 95.7 & $(5.0)$ & 96.6 & (4.5) \\
\hline \multirow[t]{4}{*}{ RT (ms) } & \multirow[t]{2}{*}{ Young } & Congr. & 373 & (34) & 409 & $(53)$ & 374 & (29) & 411 & $(42)$ & 420 & (49) \\
\hline & & Incongr. & 436 & $(45)$ & 471 & $(53)$ & 439 & (44) & 465 & (49) & 483 & (54) \\
\hline & \multirow[t]{2}{*}{ Old } & Congr. & 543 & $(85)$ & 561 & $(72)$ & 551 & $(91)$ & 569 & (79) & 576 & (64) \\
\hline & & Incongr. & 654 & (99) & 678 & $(100)$ & 669 & (109) & 689 & (101) & 690 & (80) \\
\hline \multirow[t]{4}{*}{ IES } & \multirow[t]{2}{*}{ Young } & Congr. & 379 & (36) & 411 & $(52)$ & 378 & $(30)$ & 412 & $(42)$ & 424 & (48) \\
\hline & & Incongr. & 519 & $(58)$ & 515 & $(68)$ & 524 & (78) & 519 & (85) & 529 & (59) \\
\hline & \multirow[t]{2}{*}{ Old } & Congr. & 545 & (83) & 562 & (70) & 554 & (88) & 573 & (77) & 578 & (62) \\
\hline & & Incongr. & 714 & (86) & 716 & (97) & 713 & (98) & 721 & (102) & 716 & (84) \\
\hline
\end{tabular}

Note. $\mathrm{GI}=$ gain-incentive trials; $\mathrm{GN}=$ gain-neutral trials; $\mathrm{LI}=$ loss-incentive trials; $\mathrm{LN}=$ loss-neutral trials; $\mathrm{NN}=$ neutral-neutral trials; Congr. $=$ congruent targets; Incongr. = incongruent targets

Additionally, the effect of age interacted with the effects of congruency, $F(1.0,46.0)=12.2, p=.001, \eta_{\mathrm{p}}{ }^{2}=.210$, and trial type, $F(4.0,184.0)=2.8, p=.026, \eta_{\mathrm{p}}{ }^{2}=.058$. While both younger and older adults were less accurate for incongruent relative to congruent targets $\left(p_{\mathrm{BH}}<.001\right)$, this difference was greater for younger adults. Transient effects of incentives impaired accuracy for younger adults independent of valence, as this group committed more errors in GI trials relative to GN trials $\left(p_{\mathrm{BH}}<.001\right)$, as well as in LI trials relative to LN trials $\left(p_{\mathrm{BH}}<.001\right)$. Sustained effects of incentives did not influence accuracy in younger adults $\left(p_{\mathrm{BH}}>.05\right)$. Older adults showed no effect of trial type on accuracy $\left(p_{\mathrm{BH}}>.05\right)$. Furthermore, younger adults were less accurate than older adults for GI, LI, and $\mathrm{NN}$ trials $\left(p_{\mathrm{BH}}<.05\right)$, but showed no difference for GN and $\mathrm{LN}$ trials $\left(p_{\mathrm{BH}}>.05\right)$. Lastly, there was also an interaction of Congruency $\times$ Trial Type, $F(3.6,165.18)=13.3, p<.001$, $\eta_{\mathrm{p}}{ }^{2}=.224$. Accuracy was significantly lower for incongruent relative to congruent trials $\left(p_{\mathrm{BH}}<.001\right)$ for each trial type. However, accuracy for incongruent trials was lower for GI trials relative to $\mathrm{GN}\left(p_{\mathrm{BH}}<.001\right)$, as well as for LI trials relative to $\mathrm{LN}$ trials $\left(p_{\mathrm{BH}}=.001\right)$. Accuracy was also lower for congruent targets in the GI relative to $\mathrm{GN}$ condition $\left(p_{\mathrm{BH}}=\right.$ .047).

$<$ Insert Table 2 about here.>

For RT, there were significant effects of age, $F(1.0,46.0)=$ $102.0, p<.001, \eta_{\mathrm{p}}{ }^{2}=.688$; congruency, $F(1.0,46.0)=450.4$, $p<.001, \eta_{\mathrm{p}}{ }^{2}=.907$; and trial type, $F(2.9,131.8)=26.0, p<$ $.001, \eta_{\mathrm{p}}{ }^{2}=.361$, with the effects of age and congruency interacting, $F(1.0,46.0)=42.0, p<.001, \eta_{\mathrm{p}}^{2}=.477$. On average, older adults were slower to respond than younger adults. Further, RT was significantly greater for incongruent than for congruent targets for both age groups $\left(p_{\mathrm{BH}}<.001\right)$, but this difference was larger for older adults than for younger adults. With respect to the effect of trial type, GI trials were associated with shorter RT compared with GN trials $\left(p_{\mathrm{BH}}<\right.$ .001), which was also the case for LI trials relative to $\mathrm{LN}$ trials $\left(p_{\mathrm{BH}}<.001\right)$. There was also a significant difference between $\mathrm{GN}$ and $\mathrm{NN}$ trials $\left(p_{\mathrm{BH}}=.040\right.$ ), with RT being shorter for GN trials. The comparison of $\mathrm{LN}$ trials and $\mathrm{NN}$ trials was not significant $\left(p_{\mathrm{BH}}=.120\right)$, nor were the comparisons of GI and LI trials $\left(p_{\mathrm{BH}}=.143\right)$, and $\mathrm{GN}$ and $\mathrm{LN}$ trials $\left(p_{\mathrm{BH}}=.286\right)$.

Collectively, these findings suggest that incentive-related increases in response speed may have occurred at the expense of accuracy, particularly in the case of younger adults. As described above, we further explored this relationship through a distributional analysis of the flanker interference effect on accuracy as a function of RT. The delta plots for younger and older adults are shown in Fig. 3. Analysis of the delta slopes yielded significant effects of age, $F(1,44)=17.4, p<.001$, $\eta_{\mathrm{p}}{ }^{2}=.283$, and quartile-to-quartile interval, $F(1.63,71.8)=$ $65.7, p<.001, \eta_{\mathrm{p}}{ }^{2}=.599$, as well as their interaction, $F(1.63$, $71.8)=6.55, p=.004, \eta_{\mathrm{p}}{ }^{2}=.130$. For younger adults, the quartile-to-quartile slope decreased significantly from the first interval $(M=.55, S D=.32)$ to the second $(M=.14, S D=.20$; $\left.p_{\mathrm{BH}}<.001\right)$, as well as from the second interval to the third ( $M$ $\left.=02, S D=.06 ; p_{\mathrm{BH}}=.040\right)$. Older adults, in contrast, exhibited a decrease in slope from the first interval $(M=.26, S D=$ $.23)$ to the second $\left(M=.03, S D=.08 ; p_{\mathrm{BH}}<.001\right)$, but not from the second interval to the third $(M=-.01, S D=$ $\left..03 ; p_{\mathrm{BH}}=.060\right)$. Further, at each of the three intervals, younger adults displayed significantly steeper slopes compared with older adults $\left(p_{\mathrm{BH}} \mathrm{S}<.040\right)$. This suggests that older adults engaged greater response inhibition than did younger adults, with the flanker interference 

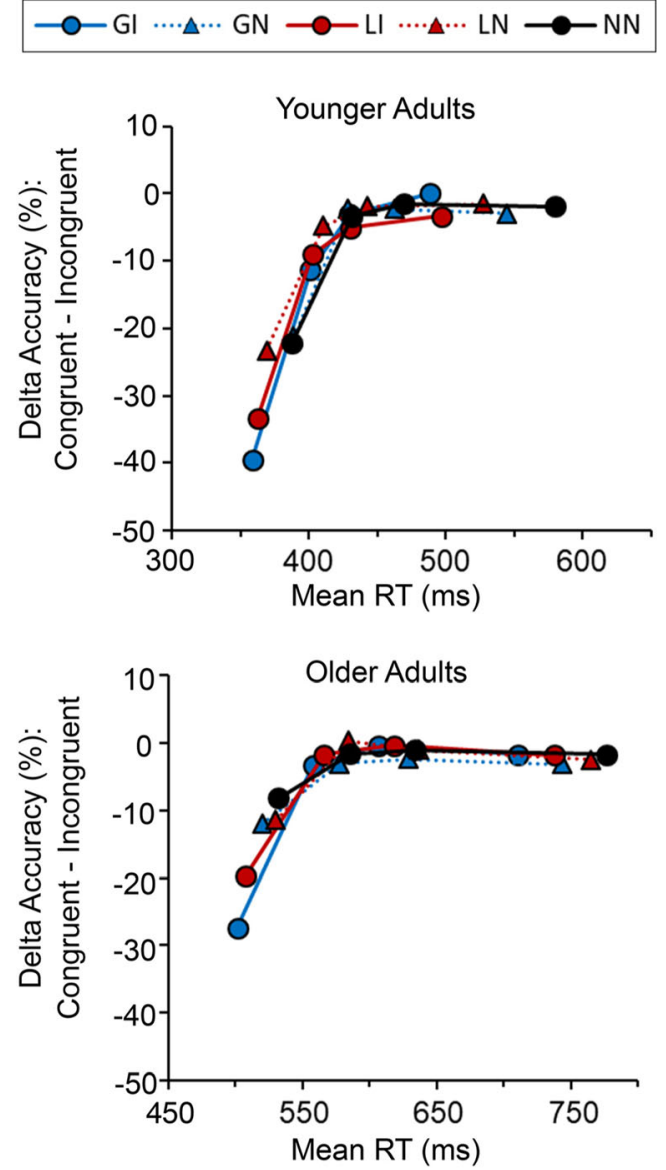

Fig. 3 Delta plots for flanker interference (accuracy) as function of RT. Each data point represents the difference in accuracy for congruent minus incongruent target responses, given the mean RT of congruent and incongruent target responses for each quartile bin. Each line corresponds to the various trial types. Plots are separated by age group. Note. Two younger adults with incomplete data sets (i.e., excluded blocks) were not included in this analysis. (Color figure online)

effect plateauing at an earlier quartile in the older adult group than in the younger adult group. Additionally there was a significant effect of trial type, $F(3.3$, 143.7) $=13.5, p<.001, \eta_{\mathrm{p}}{ }^{2}=.235$. Transient effects of gain and loss incentives influenced the quartile-toquartile slopes as greater slope values were observed for GI trials $(M=.27, S D=.23)$ relative to $\mathrm{GN}$ trials $\left(M=.11, S D=.16 ; p_{\mathrm{BH}}<.001\right)$, and for LI trials $(M$ $=.20, S D=.23)$ relative to $\mathrm{LN}$ trials $(M=.12, S D=$ $\left..13 ; p_{\mathrm{BH}}<.001\right)$, with the slopes of GI and LI trials also significantly differing $\left(p_{\mathrm{BH}}=.003\right)$. Sustained effects of incentives were not observed, as the slopes associated with $\mathrm{GN}$ and $\mathrm{LN}$ trials were equivalent to those for NN trials $\left(M=.12, S D=.13 ; p_{\mathrm{BH}} \mathrm{S}>.05\right)$. While differences related to trial type appeared to be most pronounced over the first interval, the interaction of Trial Type $\times$ Quartile-to-Quartile Interval did not reach significance, $F(5.1,224.9)=1.96, p=.084, \eta_{\mathrm{p}}^{2}$
$=.043$, nor was there a Trial Type $\times$ Age interaction, $F(3.3,143.7)=.99, p=.405, \eta_{\mathrm{p}}^{2}=.022$.

Inverse efficiency scores The ANOVA on IES revealed effects of age, $F(1.0,46.0)=95.0, p<.001, \eta_{\mathrm{p}}^{2}=.674$; trial type, $F(3.2,147.4)=5.6, p<.001, \eta_{\mathrm{p}}^{2}=.109$; and congruency, $F(1.0,46.0)=368.1, p<.001, \eta_{\mathrm{p}}^{2}=.889$, with the effect of congruency interacting with both age, $F(1.0,46.0)=5.5, p=$ $.023, \eta_{\mathrm{p}}{ }^{2}=.107$, and trial type, $F(3.87,177.9)=6.7, p<.001$, $\eta_{\mathrm{p}}{ }^{2}=.128$. In terms of the Age $\times$ Congruency interaction, both age groups displayed a significant flanker interference effect $\left(\mathrm{p}_{\mathrm{BH}}<.001\right)$, but the magnitude of this effect was larger for older adults. For the interaction of Trial Type $\times$ Congruency, incentive cues appeared to act specifically on congruent target responses. That is, transient effects of gain and loss cues were observed for congruent responses, with lower IES for GI trials relative to GN trials $\left(\mathrm{p}_{\mathrm{BH}}<.001\right)$, as well as for LI trials relative to $\mathrm{LN}$ trials $\left(\mathrm{p}_{\mathrm{BH}}<.001\right)$. There was also a sustained effect of gain, but not loss context, on congruent target responses, as IES was lower for GN trials compared with NN trials $\left(\mathrm{p}_{\mathrm{BH}}=.015\right)$, but not for $\mathrm{LN}$ trials relative to $\mathrm{NN}$ trials $\left(\mathrm{p}_{\mathrm{BH}}=.201\right)$. In contrast, no such incentive effects were present for incongruent target responses $\left(\mathrm{p}_{\mathrm{BH}}>.05\right)$.

Summary of incentive effects on behavior The distribution of the flanker interference effect on accuracy as a function of RT was indicative of reduced, rather than enhanced, response inhibition for trials in which an incentive was at stake. This effect was more pronounced for gain incentives than for loss incentives, and it was equivalent in both age groups. When this finding was taken into account through the use of IES, congruent-flanker trials showed transient effects of gains and losses, as well as a sustained effect of gains, independently of age. No incentive-based modulation was seen on incongruent trials. As such, there was no behavioral evidence to suggest that incentives aided cognitive control.

\section{Cue-locked ERP results}

Cue-P3 Means and standard deviations corresponding to all ERP amplitudes are presented in Table 3, and ERP waveforms and scalp maps illustrating the influence of trial type on cuelocked activity in younger and older adults are presented in Fig. 4. At the time of cue presentation, the peak latency of $\mathrm{P} 3$ showed an effect of age, $F(1.0,46.0)=7.2, p=.010, \eta_{\mathrm{p}}{ }^{2}=$ .136 , with this component peaking later for older adults $(M=$ $479 \mathrm{~ms}, S D=56)$ than for younger adults $(M=451 \mathrm{~ms}, S D=$ 54). No other main effect or interaction was found to influence cue-P3 latency.

Cue-P3 amplitude was influenced by region, $F(1.0$, $46.0)=47.4, p \leq .001, \eta_{\mathrm{p}}{ }^{2}=.508$, which interacted with age, $F(1.0,46.0)=34.1, p \leq .001, \eta_{\mathrm{p}}{ }^{2}=.426$. In younger adults, cue-P3 amplitude was larger at 
Table 3 Means $(M)$ and standard deviations $(S D)$ for ERP amplitudes in microvolts

\begin{tabular}{|c|c|c|c|c|c|c|c|c|c|c|c|c|}
\hline & & & \multicolumn{2}{|l|}{ GI } & \multicolumn{2}{|l|}{ GN } & \multicolumn{2}{|l|}{ LI } & \multicolumn{2}{|l|}{$\mathrm{LN}$} & \multicolumn{2}{|l|}{ NN } \\
\hline & & & $M$ & $(S D)$ & $M$ & $(S D)$ & $M$ & $(S D)$ & $M$ & $(S D)$ & $M$ & $(S D)$ \\
\hline \multirow{2}{*}{\multicolumn{2}{|c|}{$\mathrm{CNV}$}} & Young & -5.47 & $(4.5)$ & -2.90 & (2.3) & -6.06 & $(4.5)$ & -3.42 & (2.6) & -2.79 & $(2.8)$ \\
\hline & & Old & -4.55 & (3.8) & -2.64 & (3.6) & -4.01 & (3.5) & -2.44 & (3.4) & -3.36 & (3.5) \\
\hline \multirow{2}{*}{\multicolumn{2}{|c|}{ Cue-P3 (CPz, Pz) }} & Young & 7.42 & (4.1) & 3.29 & (2.3) & 6.45 & (3.5) & 3.08 & (2.8) & 1.05 & $(2.1)$ \\
\hline & & Old & 3.45 & (3.8) & 2.87 & $(3.2)$ & 3.04 & (3.1) & 1.98 & (2.4) & 1.62 & $(2.7)$ \\
\hline \multirow{2}{*}{\multicolumn{2}{|c|}{ Cue-P3 (FCz, Cz) }} & Young & 3.39 & (4.3) & 1.36 & $(2.5)$ & 2.59 & (3.7) & .97 & (3.3) & -.30 & $(2.7)$ \\
\hline & & Old & 3.11 & (3.2) & 2.43 & $(2.4)$ & 2.73 & $(2.7)$ & 1.90 & $(2.2)$ & 1.72 & $(2.4)$ \\
\hline \multirow[t]{4}{*}{ Target-P3 (CPz, Pz) } & Young & Congr. & 16.31 & $(6.2)$ & 12.97 & $(5.7)$ & 15.56 & $(6.5)$ & 12.94 & (5.6) & 11.59 & $(5.9)$ \\
\hline & & Incongr. & 15.18 & (4.7) & 13.43 & $(5.9)$ & 15.16 & (4.9) & 12.27 & (5.3) & 12.63 & $(5.1)$ \\
\hline & Old & Congr. & 12.59 & (5.4) & 11.95 & $(6.1)$ & 12.20 & $(6.5)$ & 12.19 & (5.0) & 11.94 & $(6.7)$ \\
\hline & & Incongr. & 9.74 & $(4.5)$ & 9.88 & $(4.8)$ & 10.09 & (4.7) & 9.75 & (4.4) & 9.69 & (3.8) \\
\hline \multirow[t]{4}{*}{ Target-P3 (FCz, Cz) } & Young & Congr. & 16.03 & (7.1) & 11.64 & $(6.2)$ & 15.20 & (7.2) & 11.54 & $(6.2)$ & 9.41 & $(6.0)$ \\
\hline & & Incongr. & 15.94 & (5.1) & 12.37 & $(5.9)$ & 15.45 & (5.3) & 11.35 & (5.4) & 10.62 & $(5.0)$ \\
\hline & Old & Congr. & 12.06 & (6.4) & 10.62 & $(6.6)$ & 11.49 & (7.2) & 10.93 & (5.2) & 10.61 & (6.9) \\
\hline & & Incongr. & 9.09 & $(5.7)$ & 9.11 & $(5.1)$ & 9.70 & (5.3) & 8.71 & $(4.8)$ & 8.55 & $(4.2)$ \\
\hline
\end{tabular}

Note. $\mathrm{GI}=$ gain-incentive trials; $\mathrm{GN}=$ gain-neutral trials; $\mathrm{LI}=$ loss-incentive trials; $\mathrm{LN}=$ loss-neutral trials; $\mathrm{NN}=$ neutral-neutral trials; Congr. $=$ congruent targets; Incongr. = incongruent targets

a Younger Adults
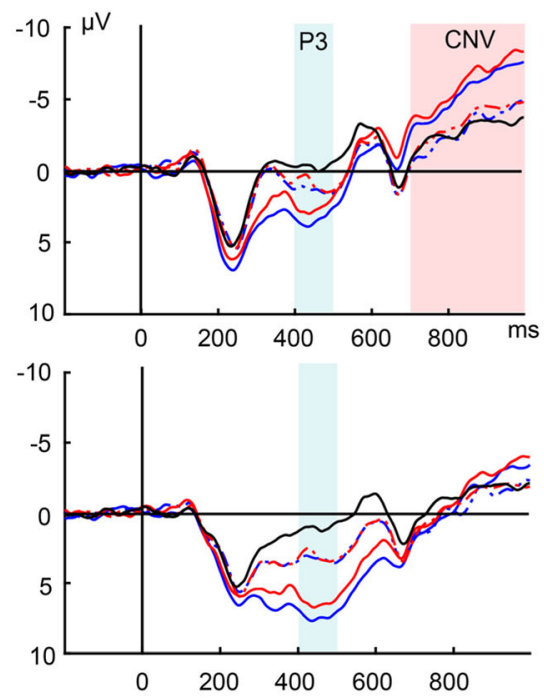

b

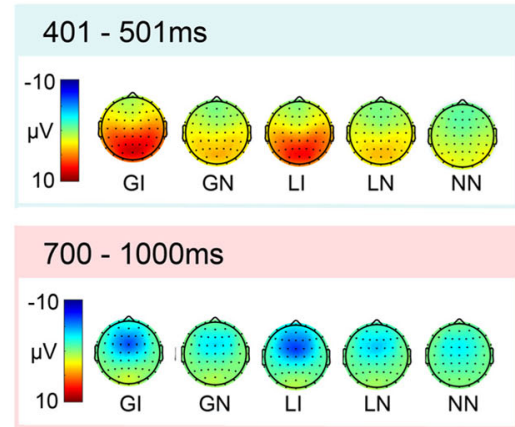

Fig. 4 Cue-locked ERP activity. Shown are (a) ERP waveforms averaged at frontocentral (top) and centroparietal sites (bottom), and (b) scalp maps averaged over the shaded regions corresponding to P3 (blue) and CNV
Older Adults
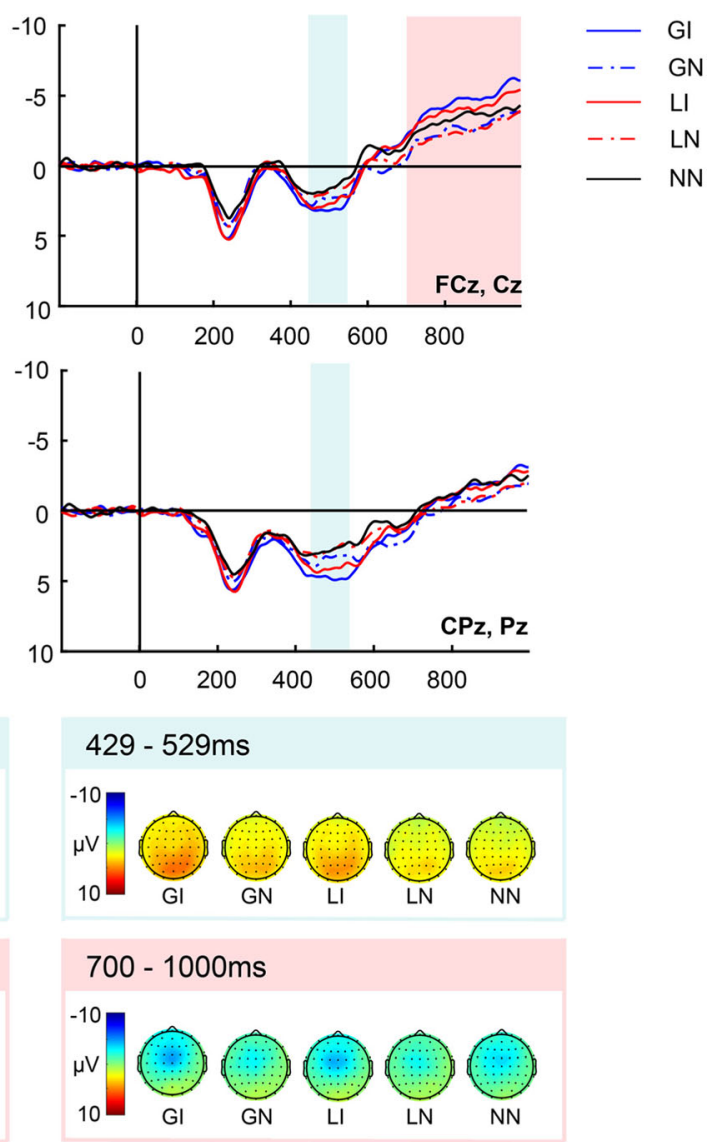

(pink).Younger adults (left) and older adults (right) are presented separately. (Color figure online) 
centroparietal sites relative to frontocentral sites $\left(p_{\mathrm{BH}}<\right.$ $.001)$. Older adults did not show this difference $\left(p_{\mathrm{BH}}=\right.$ .442). There was also an effect of trial type, $F(3.1$, 144.4) $=.23 .6, p \leq .001, \eta_{\mathrm{p}}{ }^{2}=.339$, which too interacted with age, $F(3.1,144.4)=6.7, p \leq .001, \eta_{\mathrm{p}}{ }^{2}$ $=.127$. Further, there was a three-way interaction of Age $\times$ Region $\times$ Trial Type, $F(2.98,137.3)=11.2, p$ $\leq .001, \eta_{\mathrm{p}}{ }^{2}=.196$. At both centroparietal and frontocentral sites, transient effects of gain and loss cues were observed for younger adults, with significant differences between GI and GN trials $\left(p_{\mathrm{BH}}<.01\right)$, as well as LI and LN trials $\left(p_{\mathrm{BH}}<.05\right)$. Younger adults also showed a sustained effect of gain context on cue-P3 amplitude at centroparietal and frontocentral sites, with larger amplitudes for $\mathrm{GN}$ relative to $\mathrm{NN}$ trials $\left(p_{\mathrm{BH}}<\right.$ $.05)$. In contrast, a sustained effect of loss context was present at centroparietal sites $\left(p_{\mathrm{BH}}=.003\right)$, but not frontocentral sites in younger adults $\left(p_{\mathrm{BH}}=.101\right)$. Older adults exhibited a sustained effect of gain context on cue-P3 amplitude that was specific to frontocentral sites $\left(p_{\mathrm{BH}}=.037\right)$. No other comparison on the basis of trial type was significant in older adults, at either centroparietal or frontocentral sites $\left(p_{\mathrm{BH}}>.05\right)$. Lastly, between groups, younger adults exhibited larger amplitudes for GI and LI trials relative to older adults at centroparietal sites $\left(p_{\mathrm{BH}}<.01\right)$. No other group differences were observed at centroparietal or frontocentral sites $\left(p_{\mathrm{BH}}>.05\right)$.

Contingent negative variation (CNV) A main effect of trial type, $F(3.0,140.0)=14.88, p<.001, \eta_{\mathrm{p}}{ }^{2}=.244$, but not age $F(1.0,46.0)=.68, p=.415, \eta_{\mathrm{p}}{ }^{2}=.014$, influenced CNV amplitude. CNV amplitude was more negative for GI trials relative to GN trials $\left(p_{\mathrm{BH}}<.001\right)$, as well as for LI trials relative to $\mathrm{LN}$ trials $\left(p_{\mathrm{BH}}<.001\right)$. No other comparison related to the effect of trial type was significant $\left(p_{\mathrm{BH}}>.05\right)$. There was a trend towards an interaction of Age $\times$ Trial Type that did not reach significance, $F(3.0,140.0)=2.62, p=.052, \eta_{\mathrm{p}}{ }^{2}=.054$.

\section{Summary of incentive effects on cue-locked ERP results Both} age groups exhibited transient effects of gain and loss incentive cues on CNV. In contrast, only younger adults showed transient effects of incentives on cue-P3 amplitude, at both centroparietal and frontocentral sites. Additionally, sustained incentive effects were present for cue-P3 amplitude; however, these effects differed as a function of age and region. Sustained effects were seen at centroparietal and frontocentral sites for gain blocks, and at centroparietal sites for loss blocks in younger adults. Older adults, on the other hand, showed a sustained effect of gain incentives on cue-P3 at centroparietal sites only, and did not show a sustained effect of loss incentives.

\section{Target-locked ERP results}

Target-P3 At target presentation, the latency of P3 was influenced by age, $F(1.0,46.0)=165.0, p<.001, \eta_{\mathrm{p}}{ }^{2}=.782$, with this component reaching its peak earlier in younger adults $(M$ $=423 \mathrm{~ms}, S D=67)$ compared with older adults $(M=586 \mathrm{~ms}$, $S D=60)$. The effect of congruency on target-P3 latency was also significant, $F(1.0,46.0)=18.1, p<.001, \eta_{\mathrm{p}}{ }^{2}=.282$, with this effect interacting with region, $F(1.0,46.0)=20.8, p<$ $.001, \eta_{\mathrm{p}}{ }^{2}=.311$. At centroparietal sites, P3 peaked later for incongruent targets $(M=523 \mathrm{~ms}, S D=94)$ relative to congruent targets $\left(M=485 \mathrm{~ms}, S D=97 ; p_{\mathrm{BH}}<.001\right)$. P3 latency for congruent targets $(M=499 \mathrm{~ms}, S D=103)$ did not differ from incongruent targets $(M=512 \mathrm{~ms}, S D=94)$ at frontocentral sites $\left(p_{\mathrm{BH}}=.100\right)$.

In terms of amplitude, target-P3 was influenced by region, $F(1.0,46.0)=5.8, p=.020, \eta_{\mathrm{p}}{ }^{2}=.185$, with larger amplitudes at centroparietal compared with frontocentral sites. Target congruency also influenced the amplitude of this component, $F(1.0,46.0)=10.5, p=.002, \eta_{\mathrm{p}}{ }^{2}=.185$, though this effect interacted with age, $F(1.0,46.0)=13.1, p<.001, \eta_{\mathrm{p}}{ }^{2}=.221$. As illustrated in Fig. 5, the amplitude of P3 was greater for congruent targets than for incongruent targets in older adults $\left(p_{\mathrm{BH}}=.004\right)$, whereas there was no effect of target congruency in younger adults $\left(p_{\mathrm{BH}}=.718\right)$.

With respect to the influence of the various trial types on $\mathrm{P} 3$ amplitude, there was a main effect of trial type, $F(3.2,144.8)=$ $16.6, p<.001, \eta_{\mathrm{p}}{ }^{2}=.265$, and interactions of trial type with region, $F(3.1,144.3)=15.0, p<.001, \eta_{\mathrm{p}}{ }^{2}=.246$, and with age, $F(3.2,144.8)=9.3, p<.001, \eta_{\mathrm{p}}{ }^{2}=.167$. Additionally, a three-way interaction of Age $\times$ Region $\times$ Trial Type was present, $F(3.1,144.3)=4.0, p=.008, \eta_{\mathrm{p}}{ }^{2}=.080$. ERP waveforms and scalp maps corresponding to this interaction are shown in Fig. 6. As is illustrated, older adults did not show any modulation of $\mathrm{P} 3$ amplitude by trial type, for either centroparietal or frontocentral sites $\left(p_{\mathrm{BH}}>.05\right)$. Younger adults, in contrast, exhibited transient effects of gain and loss cues, with greater amplitudes for GI trials relative to GN trials, and LI trials relative to $\mathrm{LN}$ trials, both at centroparietal and frontocentral sites $\left(p_{\mathrm{BH}}<.01\right)$. Younger adults also exhibited sustained effects of gain and loss context at frontocentral sites, with greater P3 amplitude for GN trials relative to $\mathrm{NN}$ trials $\left(p_{\mathrm{BH}}=.015\right)$ as well as LN trials relative to NN trials $\left(p_{\mathrm{BH}}=.022\right)$. These sustained incentive effects were not observed at centroparietal sites $\left(p_{\mathrm{BH}}>.05\right)$. Lastly, between groups, P3 amplitude was greater in younger adults than in older adults for GI and LI trials at centroparietal and frontocentral sites $\left(p_{\mathrm{BH}}<.05\right)$. No other differences in amplitude were observed between groups.

Summary of incentive effects on target-locked ERP results Target-P3 was influenced by incentives in younger adults, but not in older adults. In younger adults, transient effects of incentives were observed at both centroparietal and 


\section{— Congruent (Young) $\quad-\cdot \cdot \cdot \cdot$ Incongruent (Young) Congruent (Old) $\quad-\cdot \cdot \cdot$ Incongruent (Old)}
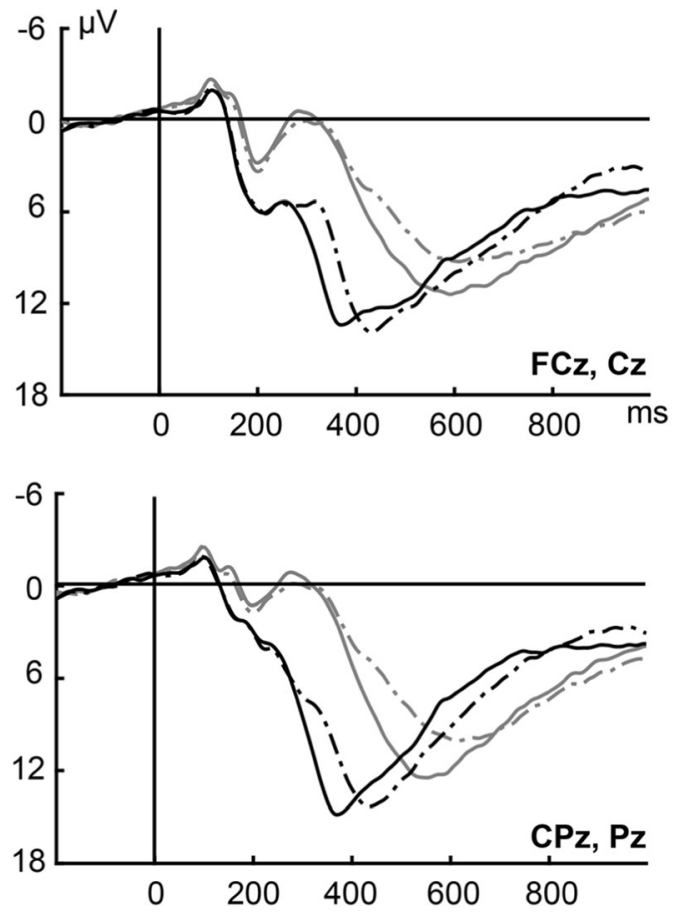

Fig. 5 Congruency effects on target-locked ERP activity averaged at frontocentral (top) and centroparietal sites (bottom) frontocentral sites, independent of incentive valence. Younger adults also exhibited sustained effects of incentives on targetP3 amplitude, but these effects were limited to frontocentral sites.

\section{Discussion}

The current study was aimed at examining the influence of monetary incentives on ERP signatures of cognitive control specific to anticipatory engagement and target processing in the context of healthy aging. The behavioral findings showed that incentives increased response speed in both age groups. This speed up came at the cost of accuracy, particularly in the younger adult group. Further exploration of the relationship between response speed and accuracy using delta plots (Ridderinkhof, 2002) revealed that, for both younger and older adults, incentives may have led to greater impulsivity, rather than control, for those trials in which individuals were fastest to respond. Indeed, examining behavioral performance through the use of inverse efficiency scores (IES), we found transient effects of gain and loss incentives, as well as sustained effects of gain incentives, to benefit congruent trials only. Notably, these trials do not require inhibition of flanker a
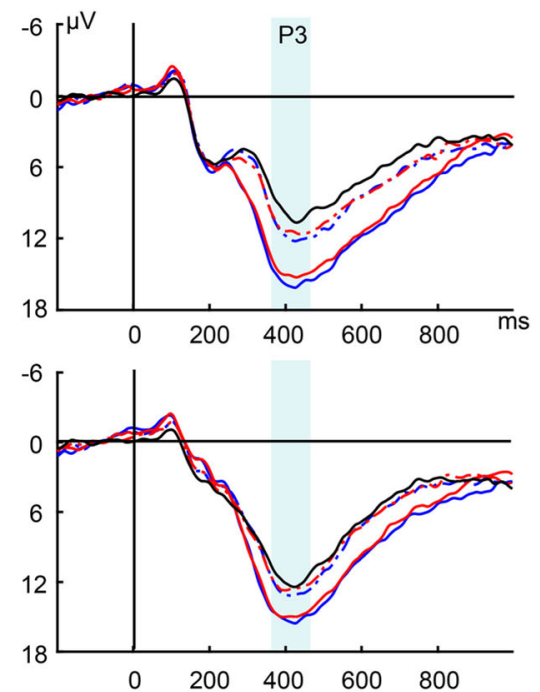

b

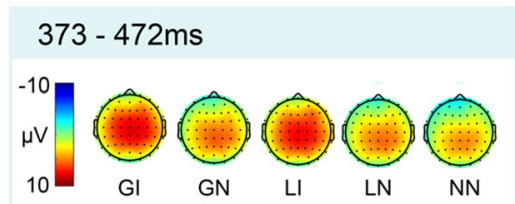

Fig. 6 Incentive effects on target-locked ERP activity. Shown are (a) ERP waveforms averaged at frontocentral (top) and centroparietal sites (bottom), and (b) scalp maps averaged over the shaded regions corresponding
Older Adults
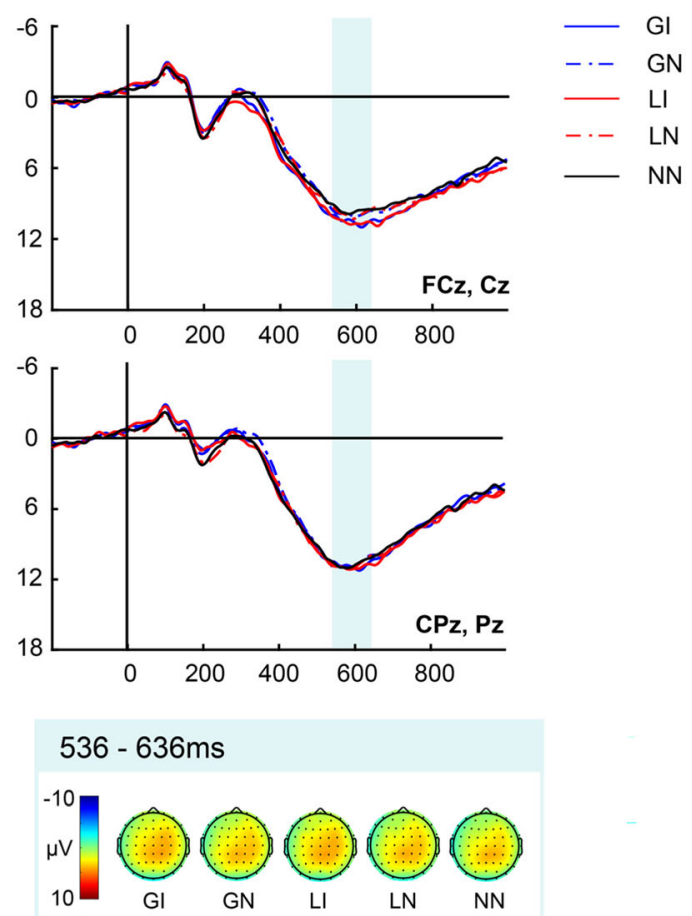

to P3.Younger adults (left) and older adults (right) are presented separately. (Color figure online) 
information. Overall, the behavioral data thus offered no evidence of incentive-based modulation of cognitive control.

The ERP results complement and qualify the behavioral findings. At cue presentation, younger adults - but not older adults - demonstrated transient incentive effects on cue-P3 amplitude at centroparietal and frontocentral sites, consistent with findings of greater modulation of this component based on cue utility in younger adults (e.g., Hämmerer et al., 2010; Kropotov et al., 2016; Schmitt et al., 2015). Younger adults also showed sustained incentive effects on cue-P3 amplitude. At centroparietal sites, this was seen for both gain and loss blocks, whereas at frontocentral sites, it occurred for gain blocks only. In older adults, the only sustained effect of incentives on cue-P3 amplitude was seen at centroparietal sites for gain blocks.

Although cue-P3 amplitude differed for younger and older adults, the ensuing CNV response was similar for younger and older adults, despite a trend towards an age difference. Both age groups showed greater cue-P3 amplitudes when incentives were at stake. Age differences emerged at the time of the target, however. Younger adults displayed both transient and sustained effects of incentives on target-P3 amplitude. In stark contrast, older adults exhibited no observable incentivebased modulation of target-P3, either at centroparietal sites or at frontocentral sites. Together, these results suggest that ERP markers of incentive-based modulation following cue and target presentation are indeed diminished in healthy aging, particularly for the P3 response.

\section{Incentive effects on cue-P3 and target-P3 amplitude differ for younger and older adults}

In line with Schmitt et al. (2015), who found decreased modulation of $\mathrm{P} 3$ at a parietal electrode in response to incentive cues in older adults, we too show greater incentive-based modulation of cue-P3 amplitude in younger adults, with this difference extending more frontally. As described in the introduction, incentive-related modulation of cue-P3 relates to functional activation of the ventral striatum (Pfabigan et al., 2014). Given that dopaminergic transmission is primarily involved in the ventral striatum response to incentive processing (de la Fuente-Fernández et al., 2002; Wolterink et al., 1993), our results are consistent with accounts of decreased dopaminergic transmission in the ventral striatum in healthy aging (Henry et al., 1986; Kaasinen et al., 2000; Rinne et al., 1993; Wang et al., 1998). We should note, however, that older adults did exhibit larger cue-P3 amplitudes for neutral cues in gain blocks relative to our baseline condition at frontocentral sites. It can thereby be suggested that older adults were more vigilant in gain blocks relative to loss and neutral blocks, though more evidence is needed to support this finding.

In addition to finding differences in P3 amplitude at the time of the cue, we also observe differences in P3 amplitude at the time of the target. In younger adults, transient and sustained effects of incentives modulated the amplitude of this component, whereas in older adults no such modulation was present. Dopaminergic activity has been linked to target-P3 amplitude in the past (Pogarell et al., 2011), and thus may also underscore reduced transmission in older adults. However, multiple neural generators are associated with target-P3 amplitude (Bledowski et al., 2004; Nieuwenhuis, Aston-Jones \& Cohen, 2005), and generally less is known regarding incentive effects on the target-P3, compared with cue-P3. Regardless, these findings suggest that future electrophysiological studies should examine the effects of incentives on both anticipatory and target-related attentional control processes.

\section{Incentives alone are not sufficient to reduce flanker interference}

In the present study, we observed an influence of incentive cues on behavior (i.e., faster responding) and target-evoked activity (i.e., increased P3 amplitude in younger adults) across congruent and incongruent flanker conditions. We did not observe a disproportionate benefit of incentives with respect to reducing perceptual conflict in the case of incongruent targets. Different explanations are possible: (a) The presence of incentives ramps up motor preparation in advance of target presentation (Roesch \& Olson, 2003); (b) Incentives produce a speed-accuracy trade-off by reducing the amount of evidence needed to generate a response (Ratcliff, 1978; Wagenmakers, Ratcliff, Gomez, \& McKoon, 2008); or (c) some combination of $a$ and $b$ (Wenzlaff, Bauer, Maess, \& Heekeren., 2011). In this regard, our findings related to the distribution of the flanker interference effect as well as CNV amplitude may be important.

Again, CNV amplitude did not significantly differ as a function of age - both younger and older adults exhibited greater CNV amplitude following incentive cues compared with neutral cues. As described previously, CNV amplitude has been related to both temporal orienting and motor response preparation (Nagai et al., 2004; Pfeuty et al., 2005). As such, it can be assumed that participants experienced a greater readiness to respond in the incentive conditions, which may have actually hindered task performance for incongruent targets. Specifically, the distributional analysis shows that increased readiness may have made it more difficult to terminate the automatic decision process described in favor of the more deliberate process as described by Ridderinkhof (2002). While age did not interact with trial type for either the CNV amplitude analysis or for the distributional analysis, inspection of the patterns hints at the possibility of age differences. Numerically, the transient effect of incentives on CNV amplitude was larger in younger adults, particularly in the case of loss incentives. Similarly, the delta plots show a pattern such that, numerically, younger adults appear to be more negatively 
affected by transient incentives at the first quartile, with this numeric age difference appearing to be larger for loss incentives.

From a broader perspective, we argue that there may have been a mismatch between the control strategy triggered by incentive cues and the task. According to the dual mechanisms of control (DMC; Braver, 2012) framework, there are two primary control modes by which attentional systems can be configured. Proactive control refers to the active maintenance of goal-relevant information recruited to meet the demands of an upcoming event, whereas reactive control is recruited when conflict is detected, particularly when the resolution of such conflict cannot be aided in advance by the proactive mode. In the current task, one can associate cue-P3 and CNV with proactive control processes by which goal-relevant information was updated (e.g., incentive availability). Target-P3, on the other hand, can be viewed as a more reactive response that was used to evaluate the target stimulus and resolve conflict. Given the CNV response observed in the current study, it appears that both younger and older adults were engaging proactive control strategies. However, because the incentives provided no information regarding the upcoming target, this strategy may have been inefficient. Indeed, previous attempts to combine flanker stimuli with incentive-related information have also failed to observe a reduction of flanker interference (e.g., Hübner \& Schlösser, 2010; Ivanov et al., 2012; Williams, Biel, Dyson, \& Spaniol, 2017). By contrast, Chiew and Braver (2016) demonstrated reduced flanker interference using incentive cues, though, only when such cues were presented in conjunction with information about the upcoming target. That is, incentive cues did not reduce flanker interference when they were presented in isolation, but did when they were combined with cues indicating the congruency of the upcoming target (Chiew \& Braver, 2016). As such, a proactive strategy may have been more beneficial in this case because properties of the target stimulus could be anticipated in advance.

\section{Target-P3 is differentially affected by flanker congruency in healthy aging}

Younger and older adults showed pronounced differences in sensitivity to flanker congruency. In particular, older adultsbut not younger adults - showed reduced target-P3 amplitudes for incongruent relative to congruent targets along the midline, despite age-equivalent congruency effects on targetP3 latency. These age-related effects of target congruency on P3 largely mirror our previous findings (i.e., Williams et al., 2016), and resemble those of Wild-Wall et al. (2008), who also find a latency effect of congruency independent of age and amplitude effect specific to older adults at a parietal electrode site. We speculate that the age differences in target-P3 amplitude may partially be accounted for by age differences in task goals. Notably, target-P3 has previously been linked to task difficulty (e.g., Hagen, Gatherwright, Lopez, \& Polich, 2006; Kim, Kim, Yoon, \& Jung, 2008). Older adults typically respond more cautiously than younger adults in speeded twoalternative forced-choice tasks, which has been attributed both to an intrinsic motivation to maintain high performance accuracy as well as a reduction in the ability to flexibly adjust decision boundaries in response to task objectives (e.g., Ratcliff, Thapar, \& McKoon, 2001; Starns \& Ratcliff, 2010, 2012). Indeed, the behavioral performance of older adults suggests that they responded more cautiously than younger adults in the present study. As such, older adults may have experienced greater difficulty when responding to incongruent relative to congruent targets. This subjective difference in difficulty may have been less pronounced in younger adults who were more willing to commit errors, as evidenced by a greater flanker interference effect on accuracy for younger adults compared with older adults.

\section{Limitations and future directions}

One limitation of the current study is the use of the same cue stimuli for gain and loss incentives. Participants may have formed a common representation for such cues, rather than forming separate associations for gains and losses, which may account for why we find few valence effects in our behavioral and ERP results. An advantage of using the same stimuli, however, was that this equated the gain and loss conditions with respect to the visual input on each trial. An additional concern is the difference in block length between neutral blocks (i.e., 48 trials/block) and incentive blocks (i.e., 96 trials/block) in that greater fatigue effects may have been present in longer blocks. If this were indeed the case, however, we would expect to see better task performance for $\mathrm{NN}$ trials compared with GN and LN trials, which was not the case. We further recognize that feedback inevitably contributed to our findings as well. Typically, feedback effects are measured in ERP experiments by examining the feedback-related negativity (FRN; Miltner, Braun, \& Coles, 1997). However, given the proportion of trials in which incentives were acquired compared with when they were not (approximately 70:30), such analyses would have been confounded by differences in both expectancy and signal-to-noise in the ERPs (Holroyd \& Krigolson, 2007; Müller, Möller, Rodriguez-Fornells \& Münte, 2006). Moreover, more is known regarding electrophysiological differences underlying feedback-based learning in younger and older adults (e.g., Eppinger \& Kray, 2011; Ferdinand \& Kray, 2013; Herbert, Eppinger \& Kray, 2011) than is the case for anticipatory and target evaluation processes, which was the focus of the present study.

Age differences in the processing of monetary rewards may have contributed to the present results. 
Studies of temporal discounting, for example, sometimes show that younger adults have a higher propensity to choose immediate over delayed rewards relative older adults (e.g., Green, Fry, \& Myerson, 1994; Eppinger, Nystrom, \& Cohen, 2012). Nonmonetary incentives, such as pleasant and unpleasant tastes (e.g., Savine et al., 2010), or social rewards (e.g., Rademacher, Salama, Gründer, \& Spreckelmeyer, 2014), may produce a different pattern of age and valence effects on the time course of cognitive control. Investigating the possibility of an age-related positivity effect in cognitive control using nonmonetary incentives is an interesting avenue for future research.

An additional limitation of the current study is that our observation of CNV was constrained by the duration between cue and target onset. As such, the time window that we use to measure $\mathrm{CNV}$ occurs earlier and is shorter in duration than that used in previous studies (e.g., Funderud et al., 2012; Gómez et al., 2007; Plichta et al., 2013). Consideration of differences in the time window used should be heeded when interpreting the results of the present study alongside other studies concerned with the CNV. Related to this point, the involvement of particular neural structures and processes can only be inferred in the present study. As described previously, however, there are a number of fMRI studies in this area (e.g., Dreher et al., 2008; Samanez-Larkin et al., 2007; Schott et al., 2007; Spaniol et al., 2015; Vink et al., 2015) whereas very little work examining electrophysiological observations exist (e.g., Schmitt et al., 2015). Thus, unlike much of the work to date, we are able to make observations at the time of cue and target presentation with high temporal precision. Ideally, future research will combine EEG with fMRI to examine anticipatory engagement and target processing in relation to incentive-based effects using healthy older adult populations. Such studies would be valuable in confirming whether the neural mechanisms underlying the ERP signatures described previously for younger adults (e.g., Pfabigan et al., 2014; Plichta et al., 2013) are the same for older adults.

As we mention above, incentives in the present task were not sufficient to reduce flanker interference effects. While this does not necessarily contradict the idea that incentives work to engage attentional control processes, it is important that future studies with younger and older adults employ tasks in which incentive information can be used to resolve stimulus conflict. This could involve not only providing incentive and neutral cues prior to target onset but also associating these cues with specific target features (e.g., color; Egner et al., 2008), which would permit participants to engage proactive control mechanisms more effectively.

\section{Conclusions}

Our main finding is that $\mathrm{P} 3$ amplitude is less influenced by transient or sustained effects of incentives in older adults than is the case for younger adults, for both cue and target stimuli. Curiously, in the present task, the age differences identified in the ERP do not seem to impact behavioral responses, at least as measured by RT. We believe two complementary factors account for this discrepancy. First, modulation of the CNV component is similar for younger and older adults. This component is associated with response preparation and may have paradoxically made it more difficult to override incorrect responses to flanker stimuli when incentives were present. Second, incentives may need to be paired with cues that offer some predictive value regarding some feature of the target stimulus (e.g., Chiew \& Braver, 2016) to produce enhanced cognitive control in the face of interference. Such cues were not provided in the current paradigm, limiting the degree to which age differences in incentive-based modulation of cognitive control could be expressed behaviorally. Overall, these findings provide novel insights into transient and sustained electrophysiological activity associated with anticipation and target evaluation in incentive-based contexts in healthy aging.

Acknowledgements We thank Carson Pun for technical support during data collection and data analysis. We also thank Laura Bianchi and Ryan Marinacci for their assistance with data collection. This research was supported by a grant from the Natural Sciences and Engineering Research Council (DG\# 358797 to J.S.), by the Canada Research Chair program (J.S.), and by an Early Researcher Award from the Ontario Ministry of Research and Innovation (J.S.)

\section{References}

Bekker, E. M., Kenemans, J. L., \& Verbaten, M. N. (2004). Electrophysiological correlates of attention, inhibition, sensitivity and bias in a continuous performance task. Clinical Neurophysiology, 115, 2001-2013.

Benjamini, Y., \& Hochberg, Y. (1995). Controlling the false discovery rate: A practical and powerful approach to multiple testing. Journal of the Royal Statistical Society, Series B (Methodological), 57, 289300.

Bledowski, C., Prvulovic, D., Hoechstetter, K., Scherg, M., Wibral, M., Goebel, R., \& Linden, D. E. (2004). Localizing P300 generators in visual target and distractor processing: A combined event-related potential and functional magnetic resonance imaging study. Journal of Neuroscience, 24, 9353-9360.

Braver, T. S. (2012). The variable nature of cognitive control: A dual mechanisms framework. Trends in Cognitive Sciences, 16, 106-113.

Broyd, S. J., Richards, H. J., Helps, S. K., Chronaki, G., Bamford, S., \& Sonuga-Barke, E. J. (2012). An electrophysiological monetary incentive delay (e-MID) task: A way to decompose the different components of neural response to positive and negative monetary reinforcement. Journal of Neuroscience Methods, 209, 40-49.

Carter, R. M., MacInnes, J. J., Huettel, S. A., \& Adcock, R. A. (2009). Activation in the VTA and nucleus accumbens increases in 
anticipation of both gains and losses. Frontiers in Behavioral Neuroscience, 3, 21.

Carver, C. S., \& White, T. L. (1994). Behavioral inhibition, behavioral activation, and affective responses to impending reward and punishment: The BIS/BAS scales. Journal of Personality and Social Psychology, 67, 319-333.

Chiew, K. S., \& Braver, T. S. (2013). Temporal dynamics of motivationcognitive control interactions revealed by high-resolution pupillometry. Frontiers in Psychology, 4, 15.

Chiew, K. S., \& Braver, T. S. (2016). Reward favors the prepared: Incentive and task-informative cues interact to enhance attentional control. Journal of Experimental Psychology: Human Perception and Performance, 42, 52-66.

Cho, Y. T., Fromm, S., Guyer, A. E., Detloff, A., Pine, D. S., Fudge, J. L., \& Ernst, M. (2013). Nucleus accumbens, thalamus and insula connectivity during incentive anticipation in typical adults and adolescents. NeuroImage, 66, 508-521.

Chowdhury, R., Guitart-Masip, M., Lambert, C., Dayan, P., Huys, Q., Düzel, E., \& Dolan, R. J. (2013). Dopamine restores reward prediction errors in old age. Nature Neuroscience, 16, 648-653.

Corbetta M, Patel G, Shulman GL (2008) The Reorienting System of the Human Brain: From Environment to Theory of Mind. Neuron 58(3): 306-324

Dambacher, M., \& Hübner, R. (2015). Time pressure affects the efficiency of perceptual processing in decisions under conflict. Psychological Research, 79, 83-94.

de la Fuente-Fernández, R., Phillips, A. G., Zamburlini, M., Sossi, V., Calne, D. B., Ruth, T. J., \& Stoessl, A. J. (2002). Dopamine release in human ventral striatum and expectation of reward. Behavioural Brain Research, 136, 359-363.

Delorme, A., \& Makeig, S. (2004). EEGLAB: An open source toolbox for analysis of single-trial EEG dynamics including independent component analysis. Journal of Neuroscience Methods, 134, 9-21.

Delorme, A., Sejnowski, T., \& Makeig, S. (2007). Enhanced detection of artifacts in EEG data using higher-order statistics and independent component analysis. NeuroImage, 34, 1443-1449.

Dreher, J. C., Meyer-Lindenberg, A., Kohn, P., \& Berman, K. F. (2008). Age-related changes in midbrain dopaminergic regulation of the human reward system. Proceedings of the National Academy of Sciences, 105, 15106-15111.

Egner, T., Monti, J. M., Trittschuh, E. H., Wieneke, C. A., Hirsch, J., \& Mesulam, M. M. (2008). Neural integration of top-down spatial and feature-based information in visual search. Journal of Neuroscience, 28, 6141-6151.

Eppinger, B., \& Kray, J. (2011). To choose or to avoid: Age differences in learning from positive and negative feedback. Journal of Cognitive Neuroscience, 23(1), 41-52.

Eppinger, B., Nystrom, L. E., \& Cohen, J. D. (2012). Reduced sensitivity to immediate reward during decision-making in older than younger adults. PLOS ONE, 7, e36953.

Eriksen, B. A., \& Eriksen, C. W. (1974). Effects of noise letters upon the identification of a target letter in a nonsearch task. Attention, Perception, \& Psychophysics, 16, 143-149.

Ferdinand, N. K., \& Kray, J. (2013). Age-related changes in processing positive and negative feedback: Is there a positivity effect for older adults? Biological Psychology, 94(2), 235-241.

Funderud, I., Lindgren, M., Løvstad, M., Endestad, T., Voytek, B., Knight, R. T., \& Solbakk, A. K. (2012). Differential go/nogo activity in both contingent negative variation and spectral power. PLOS ONE, 7, e48504.

Folstein, M. F., Folstein, S. E., \& McHugh, P. R. (1975). "Mini-mental state": A practical method for grading the cognitive state of patients for the clinician. Journal of Psychiatric Research, 12, 189-198.

Gajewski, P. D., Stoerig, P., \& Falkenstein, M. (2008). ERP—Correlates of response selection in a response conflict paradigm. Brain Research, 1189, 127-134.
Gillebert, C. R., Mantini, D., Thijs, V., Sunaert, S., Dupont, P., \& Vandenberghe, R. (2011). Lesion evidence for the critical role of the intraparietal sulcus in spatial attention. Brain, 134, 1694-1709.

Gómez, C. M., Flores, A., \& Ledesma, A. (2007). Fronto-parietal networks activation during the contingent negative variation period. Brain Research Bulletin, 73, 40-47.

Green, L., Fry, A. F., \& Myerson, J. (1994). Discounting of delayed rewards: A life-span comparison. Psychological Science, 5, 33-36.

Hagen, G. F., Gatherwright, J. R., Lopez, B. A., \& Polich, J. (2006). P3a from visual stimuli: Task difficulty effects. International Journal of Psychophysiology, 59, 8-14.

Hämmerer, D., Li, S. C., Müller, V., \& Lindenberger, U. (2010). An electrophysiological study of response conflict processing across the lifespan: Assessing the roles of conflict monitoring, cue utilization, response anticipation, and response suppression. Neuropsychologia, 48, 3305-3316.

Henry, J. M., Filburn, C. R., Joseph, J. A., \& Roth, G. S. (1986). Effect of aging on striatal dopamine receptor subtypes in Wistar rats. Neurobiology of Aging, 7, 357-361.

Herbert, M., Eppinger, B., \& Kray, J. (2011). Younger but not older adults benefit from salient feedback during learning. Frontiers in Psychology, 2, 171.

Holroyd, C. B., \& Krigolson O. E. (2007). Reward prediction error signals associated with a modified time estimation task. Psychophysiology, 44, 913-917.

Hopfinger, J. B., Buonocore, M. H., \& Mangun, G. R. (2000). The neural mechanisms of top-down attentional control. Nature Neuroscience, 3, 284-291.

Hübner, R., \& Schlösser, J. (2010). Monetary reward increases attentional effort in the flanker task. Psychonomic Bulletin \& Review, 17, 821826.

Ivanov, I., Liu, X., Clerkin, S., Schulz, K., Friston, K., Newcorn, J. H., \& Fan, J. (2012). Effects of motivation on reward and attentional networks: An fMRI study. Brain and Behavior, 2, 741-753.

Jimura, K., Locke, H. S., \& Braver, T. S. (2010). Prefrontal cortex mediation of cognitive enhancement in rewarding motivational contexts. Proceedings of the National Academy of Sciences, 107, 8871-8876.

Jonkman, L. M. (2006). The development of preparation, conflict monitoring and inhibition from early childhood to young adulthood: A go/no-go ERP study. Brain Research, 1097, 181-193.

Kaasinen, V., Vilkman, H., Hietala, J., Någren, K., Helenius, H., Olsson, H., . . \& R Rinne, J. O. (2000). Age-related dopamine D2/D3 receptor loss in extrastriatal regions of the human brain. Neurobiology of Aging, 21, 683-688.

Kim, K. H., Kim, J. H., Yoon, J., \& Jung, K. Y. (2008). Influence of task difficulty on the features of event-related potential during visual oddball task. Neuroscience Letters, 445(2), 179-183.

Knutson, B., Westdorp, A., Kaiser, E., \& Hommer, D. (2000). FMRI visualization of brain activity during a monetary incentive delay task. NeuroImage, 12, 20-27.

Kool, W., \& Botvinick, M. (2014). A labor/leisure tradeoff in cognitive control. Journal of Experimental Psychology: General, 143, 131141.

Kray, J., Eppinger, B., \& Mecklinger, A. (2005). Age differences in attentional control: An event-related potential approach. Psychophysiology, 42, 407-416.

Krebs, R. M., Boehler, C. N., Appelbaum, L. G., \& Woldorff, M. G. (2013). Reward associations reduce behavioral interference by changing the temporal dynamics of conflict processing. PLOS ONE, 8, e53894.

Krebs, R. M., Boehler, C. N., Roberts, K. C., Song, A. W., \& Woldorff, M. G. (2012). The involvement of the dopaminergic midbrain and cortico-striatal-thalamic circuits in the integration of reward prospect and attentional task demands. Cerebral Cortex, 22, 607-615. 
Krebs, R. M., Boehler, C. N., \& Woldorff, M. G. (2010). The influence of reward associations on conflict processing in the Stroop task. Cognition, 117, 341-347.

Kropotov, J., Ponomarev, V., Tereshchenko, E. P., Müller, A., \& Jäncke, L. (2016). Effect of aging on ERP components of cognitive control. Frontiers in Aging Neuroscience, 8, 69. doi:https://doi.org/10.3389/ fnagi.2016.00069

Lopez-Calderon, J., \& Luck, S. J. (2014). ERPLAB: An open-source toolbox for the analysis of event-related potentials. Frontiers in Human Neuroscience, 8, 213.

Lovibond, P. F., \& Lovibond, S. H. (1995). The structure of negative emotional states: Comparison of the Depression Anxiety Stress Scales (DASS) with the Beck Depression and Anxiety Inventories. Behaviour Research and Therapy, 33, 335-343.

Marini, F., van den Berg, B., \& Woldorff, M. G. (2015). Reward prospect interacts with trial-by-trial preparation for potential distraction. Visual Cognition, 23(1), 313-335.

Massar, S. A., Lim, J., Sasmita, K., \& Chee, M. W. (2016). Rewards boost sustained attention through higher effort: A value-based decision making approach. Biological Psychology, 120, 21-27.

Mather, M., \& Carstensen, L. L. (2005). Aging and motivated cognition: The positivity effect in attention and memory. Trends in Cognitive Sciences, 9, 496-502.

Mell, T., Wartenburger, I., Marschner, A., Villringer, A., Reischies, F. M., \& Heekeren, H. R. (2009). Altered function of ventral striatum during reward-based decision making in old age. Frontiers in Human Neuroscience, 3, 34.

Miltner, W. H. R., Braun, C. H., \& Coles M. G. H. (1997). Event related brain potentials following incorrect feedback in a time estimation task: Evidence for a generic neural system for error detection. Journal of Cognitive Neuroscience, 9, 787-796.

Müller, S. V., Möller, J., Rodriguez-Fornells, A., \& Münte, T. F. (2006). Brain potentials related to self-generated and external information used for performance monitoring. Clinical Neurophysiology, 116, 63-741.

Nagai, Y., Critchley, H. D., Featherstone, E., Fenwick, P. B. C., Trimble, M. R., \& Dolan, R. J. (2004). Brain activity relating to the contingent negative variation: An fMRI investigation. NeuroImage, 21, 1232-1241.

Nieuwenhuis, S., Aston-Jones, G., \& Cohen, J. D. (2005). Decision making, the P3, and the locus coeruleus-Norepinephrine system. Psychological Bulletin, 131, 510-532.

Padmala, S., \& Pessoa, L. (2011). Reward reduces conflict by enhancing attentional control and biasing visual cortical processing. Journal of Cognitive Neuroscience, 23, 3419-3432.

Pfabigan DM, Seidel E-M, Sladky R, Hahn A, Paul K, Grahl A, Küblböck M, Kraus C, Hummer A, Kranz GS, Windischberger C, Lanzenberger R, Lamm C (2014) P300 amplitude variation is related to ventral striatum BOLD response during gain and loss anticipation: An EEG and fMRI experiment. NeuroImage 96:12-21

Pfeuty, M., Ragot, R., \& Pouthas, V. (2005). Relationship between CNV and timing of an upcoming event. Neuroscience Letters, 382, 106111 .

Plichta MM, Wolf I, Hohmann S, Baumeister S, Boecker R, Schwarz AJ, Zangl M, Mier D, Diener C, Meyer P, Holz N, Ruf M, Gerchen MF, Bernal-Casas D, Kolev V, Yordanova J, Flor H, Laucht M, Banaschewski T, Kirsch P, Meyer-Lindenberg A, Brandeis D (2013) Simultaneous EEG and fMRI Reveals a Causally Connected Subcortical-Cortical Network during Reward Anticipation. J Neurosci 33(36):14526-14533

Pogarell, O., Padberg, F., Karch, S., Segmiller, F., Juckel, G., Mulert, C., . . . \& Koch, W. (2011). Dopaminergic mechanisms of target detection-P300 event related potential and striatal dopamine. Psychiatry Research: Neuroimaging, 194(3), 212-218.

Polich, J. (2007). Updating P300: An integrative theory of P3a and P3b. Clinical Neurophysiology, 118, 2128-2148.
Purmann, S., Badde, S., Luna-Rodriguez, A., \& Wendt, M. (2011). Adaptation to frequent conflict in the Eriksen flanker task. Journal of Psychophysiology, 25, 50-59.

Rademacher, L., Salama, A., Gründer, G., \& Spreckelmeyer, K. N. (2014). Differential patterns of nucleus accumbens activation during anticipation of monetary and social reward in young and older adults. Social Cognitive and Affective Neuroscience, 9, 825-831.

Ratcliff, R. (1978). A theory of memory retrieval. Psychological Review, $85,59-108$.

Ratcliff, R., Thapar, A., \& McKoon, G. (2001). The effects of aging on reaction time in a signal detection task. Psychology and Aging, 16, 323-341.

Raven, J. C. (1982). Revised manual for Raven's Progressive Matrices and Vocabulary Scales. San Antonio, TX: Psychological Corporation.

Reed, A. E., \& Carstensen, L. L. (2012). The theory behind the agerelated positivity effect. Frontiers in Psychology, 3. doi:https://doi. org/10.3389/fpsyg.2012.00339

Reuter, E. M., Voelcker-Rehage, C., Vieluf, S., Lesemann, F. P., \& Godde, B. (2016). The P3 parietal-to-frontal shift relates to agerelated slowing in a selective attention task. Journal of Psychophysiology, 31, 1-18.

Ridderinkhof, K. R. (2002). Activation and suppression in conflict tasks: Empirical clarification through distributional analyses. In W. Prinz \& B. Hommel (Eds.), Common Mechanisms in Perception and Action: Attention \& performance (Vol. 19, pp. 494-519). Oxford, UK: Oxford University Press.

Ridderinkhof, K. R., Scheres, A., Oosterlaan, J., \& Sergeant, J. A. (2005). Delta plots in the study of individual differences: New tools reveal response inhibition deficits in $\mathrm{AD} / \mathrm{HD}$ that are eliminated by methylphenidate treatment. Journal of Abnormal Psychology, 114, 197.

Rinne, J. O., Hietala, J., Ruotsalainen, U., Säkö, E., Laihinen, A., Någren, K., . . \& \& Syvälahti, E. (1993). Decrease in human striatal dopamine D2 receptor density with age: A PET study with [11C] raclopride. Journal of Cerebral Blood Flow \& Metabolism, 13, 310-314.

Roelofs, A., Piai, V., \& Rodriguez, G. G. (2011). Attentional inhibition in bilingual naming performance: Evidence from delta-plot analyses. Frontiers in Psychology, 2. doi:https://doi.org/10.3389/fpsyg.2011. 00184

Roesch, M. R., \& Olson, C. R. (2003). Impact of expected reward on neuronal activity in prefrontal cortex, frontal and supplementary eye fields and premotor cortex. Journal of Neurophysiology, 90, 17661789.

Samanez-Larkin, G. R., Gibbs, S. E., Khanna, K., Nielsen, L., Carstensen, L. L., \& Knutson, B. (2007). Anticipation of monetary gain but not loss in healthy older adults. Nature Neuroscience, 10 , 787-791.

Savine, A. C., Beck, S. M., Edwards, B. G., Chiew, K. S., \& Braver, T. S. (2010). Enhancement of cognitive control by approach and avoidance motivational states. Cognition and Emotion, 24, 338-356.

Schevernels, H., Bombeke, K., Krebs, R. M., \& Boehler, C. N. (2016). Preparing for (valenced) action: The role of differential effort in the orthogonalized go/nogo task. Psychophysiology, 53, 186-197.

Schevernels, H., Krebs, R. M., Santens, P., Woldorff, M. G., \& Boehler, C. N. (2014). Task preparation processes related to reward prediction precede those related to task-difficulty expectation. NeuroImage, 84, 639-647.

Schmitt, H., Ferdinand, N. K., \& Kray, J. (2015). The influence of monetary incentives on context processing in younger and older adults: An event-related potential study. Cognitive, Affective, \& Behavioral Neuroscience, 15, 416-434.

Schott, B. H., Minuzzi, L., Krebs, R. M., Elmenhorst, D., Lang, M., Winz, O. H., . . . \& Düzel, E. (2008). Mesolimbic functional magnetic resonance imaging activations during reward anticipation correlate with reward-related ventral striatal dopamine release. Journal of Neuroscience, 28, 14311-14319. 
Schott, B. H., Niehaus, L., Wittmann, B. C., Schütze, H., Seidenbecher, C. I., Heinze, H. J., \& Düzel, E. (2007). Ageing and early-stage Parkinson's disease affect separable neural mechanisms of mesolimbic reward processing. Brain, 130, 2412-2424.

Spaniol, J., Bowen, H. J., Wegier, P., \& Grady, C. (2015). Neural responses to monetary incentives in younger and older adults. Brain Research, 1612, 70-82.

Starns, J. J., \& Ratcliff, R. (2010). The effects of aging on the speedaccuracy compromise: Boundary optimality in the diffusion model. Psychology and Aging, 25, 377-390.

Starns, J. J., \& Ratcliff, R. (2012). Age-related differences in diffusion model boundary optimality with both trial-limited and time-limited tasks. Psychonomic Bulletin \& Review, 19, 139-145.

Tom, S. M., Fox, C. R., Trepel, C., \& Poldrack, R. A. (2007). The neural basis of loss aversion in decision-making under risk. Science, 315 , $515-518$.

Townsend, J. T., \& Ashby, F. G. (1978). Methods of modeling capacity in simple processing systems. In J. N. J. Castellan \& F. Restle (Eds.), Cognitive theory (pp. 199-239). New York, NY: Erlbaum.

van den Berg, B., Krebs, R. M., Lorist, M. M., \& Woldorff, M. G. (2014). Utilization of reward-prospect enhances preparatory attention and reduces stimulus conflict. Cognitive, Affective, \& Behavioral Neuroscience, 14, 561-577.

Vink, M., Kleerekooper, I., van den Wildenberg, W. P., \& Kahn, R. S. (2015). Impact of aging on frontostriatal reward processing. Human Brain Mapping, 36, 2305-2317.

Wagenmakers, E. J., Ratcliff, R., Gomez, P., \& McKoon, G. (2008). A diffusion model account of criterion shifts in the lexical decision task. Journal of Memory and Language, 58(1), 140-159.

Wang, Y., Chan, G. L., Holden, J. E., Dobko, T., Mak, E., Schulzer, M., . . . \& Stoessl, A. J. (1998). Age-dependent decline of dopamine D1 receptors in human brain: A PET study. Synapse, 30, 56-61.

Watson, D., Clark, L. A., \& Tellegen, A. (1988). Development and validation of brief measures of positive and negative affect: The
PANAS scales. Journal of Personality and Social Psychology, 54, 1063-1070.

Wechsler, D. (1955). Wechsler Adult Intelligence Scale: Manual. New York, NY: Psychological Corporation.

Weiler, J. A., Bellebaum, C., \& Daum, I. (2008). Aging affects acquisition and reversal of reward-based associative learning. Learning \& Memory, 15, 190-197.

Wenzlaff, H., Bauer, M., Maess, B., \& Heekeren, H. R. (2011). Neural characterization of the speed-accuracy tradeoff in a perceptual decision-making task. Journal of Neuroscience, 31, 1254-1266.

Westbrook, A., \& Braver, T. S. (2015). Cognitive effort: A neuroeconomic approach. Cognitive, Affective, \& Behavioral Neuroscience, 15, 395-415.

Wolterink, G., Phillips, G., Cador, M., Donselaar-Wolterink, I., Robbins, T. W., \& Everitt, B. J. (1993). Relative roles of ventral striatal D 1 and $\mathrm{D} 2$ dopamine receptors in responding with conditioned reinforcement. Psychopharmacology, 110, 355-364.

Wild-Wall, N., Falkenstein, M., \& Hohnsbein, J. (2008). Flanker interference in young and older participants as reflected in event-related potentials. Brain Research, 1211, 72-84.

Wild-Wall, N., Hohnsbein, J., \& Falkenstein, M. (2007). Effects of ageing on cognitive task preparation as reflected by event-related potentials. Clinical Neurophysiology, 118(3), 558-569.

Williams, R. S., Biel, A. L., Dyson, B. J., \& Spaniol, J. (2017). Age differences in gain-and loss-motivated attention. Brain and Cognition, 111, 171-181.

Williams, R. S., Biel, A. L., Wegier, P., Lapp, L. K., Dyson, B. J., \& Spaniol, J. (2016). Age differences in the Attention Network Test: Evidence from behavior and event-related potentials. Brain and Cognition, 102, 65-79.

Wylie, S. A., Ridderinkhof, K. R., Eckerle, M. K., \& Manning, C. A. (2007). Inefficient response inhibition in individuals with mild cognitive impairment. Neuropsychologia, 45, 1408-1419. 